\title{
Mechanism and Unidirectionality of the Electron Transfer in the Photosynthetic Reaction Center of Rhodopseudomonas Viridis: SAC-CI Theoretical Study
}

\author{
J. Hasegawa ${ }^{\dagger}$ and H. Nakatsuji ${ }^{*}, \dagger$ \\ Department of Synthetic Chemistry and Biological Chemistry, Graduate School of Engineering, \\ Kyoto University, Sakyo-ku, Kyoto 606-8501, Japan, and Institute for Fundamental Chemistry, \\ 34-4 Takano Nishi-hiraki-cho, Sakyo-ku, Kyoto 606-8103, Japan
}

Received: July 2, 1998; In Final Form: September 16, 1998

\begin{abstract}
The electronic mechanism and the origin of the unidirectionality of the electron transfer from photoexcited special pair to bacteriopheophytin in the photosynthetic reaction center (PSRC) of Rhodopseudomonas (Rps) viridis are studied theoretically by using the SAC(symmetry adapted cluster)-CI (configuration interaction) method. The effects of the surrounding proteins are considered by using the point charge model. The L-branch selectivity of the electron transfer is explained by the asymmetry of the transfer integral, an electronic factor, which originates from a small structural asymmetry of the PSRC: the L-side chromophores are locally closer than the M-side ones, though the average separations are almost the same. The smallness of the charge recombination rate is attributed to the difference in the electron localization between the LUMO and HOMO of special pair. Protein effects on the unidirectionality are quite small as far as the electrostatic model is valid, though the proteins keep the three-dimensional arrangement of the chromophores in the PSRC. A mutation experiment for realizing M-side selectivity is suggested.
\end{abstract}

\section{Introduction}

Photosynthetic reaction center (PSRC) converts photon energy into chemical energy through charge separations and initiates biochemical reaction cycles. ${ }^{1}$ The structure of the PSRC of Rhodopseudomonas viridis (Rps. viridis) was determined by $\mathrm{X}$-ray crystallography ${ }^{2}$ and we show in Figure 1 the L- and M-branches which contain seven chromophores arranged in a pseudo $C_{2}$ symmetry. They are special pair $(\mathrm{P}$, bacteriochlorophyll $b$ dimer), two bacteriochlorophylls $b$ ( $\mathrm{B}_{\mathrm{L}}$ and $\left.\mathrm{B}_{\mathrm{M}}\right)$, two bacteriopheophytins $b\left(\mathrm{H}_{\mathrm{L}}\right.$ and $\left.\mathrm{H}_{\mathrm{M}}\right)$, menaquinone (MQ), and ubiquinone (UQ) which are supported by the proteins consisting of about 1200 residues. The PSRC is embedded in the membrane proteins. Interestingly, the electron transfer (ET) in the PSRC occurs unidirectionally: ${ }^{3,4}$ the electron in the excited state of $\mathrm{P}\left(\mathrm{P}^{*}\right)$ is transferred asymmetrically only along the L-branch, despite of its almost symmetrical alignment. The ET is known to be fast, long-range, and significantly efficient. ${ }^{1}$ The ET from $\mathrm{P}^{*}$ to $\mathrm{H}$ occurs in $3 \times 10^{-12} \mathrm{~s}$, from $\mathrm{H}^{-}$to MQ in 200 $\times 10^{-12} \mathrm{~s}$, and from MQ to UQ in $100 \times 10^{-6} \mathrm{~s} .^{1}$ The first step, which is the main subject of the present study, is a very fast process.

Marcus gave a basic formula describing the rate constant of the ET reaction in a condensed medium as ${ }^{5}$

$$
k=\frac{2 \pi}{\hbar}\left|H_{\mathrm{IF}}\right|^{2} \frac{1}{(4 \pi \lambda R T)^{1 / 2}} \exp \left\{-\frac{(\Delta G+\lambda)^{2}}{4 \lambda R T}\right\}
$$

where $H_{\mathrm{IF}}$ is the transfer integral which describes the electronic coupling between the initial and final states. $\Delta G$ is the free energy difference between the initial and final states and $\lambda$ the reorganization energy associated with the ET reaction. This

* To whom correspondence should be addressed.

Department of Synthetic Chemistry and Biological Chemistry.

$\doteqdot$ Institute for Fundamental Chemistry. formula may be viewed as consisting of two factors: electronic and thermodynamic. The former consists of the transfer integral part and represents the width of the electron-transfer pathway. The latter consists of the rest part depending on the energetics of the system and shows a thermodynamic control.

On the basis of this formula, several theoretical studies were performed to clarify the underlying mechanism of the electron transfer and its unidirectionality. The energetics of this system was studied by semiempirical quantum-chemical calculations, 6,7 electrostatic calculations, ${ }^{8,9}$ and molecular dynamics simulation calculations. ${ }^{10}$ These studies concluded that the ET along the L-branch is energetically favorable mainly due to the protein electrostatic and electric-field effects. ${ }^{6,8-10}$ The transfer integrals were also calculated using the semiempirical wave functions. ${ }^{7,8,11}$ In particular, Jortner and co-workers ${ }^{8,11}$ attributed the unidirectionality as being due to the geometrical and electronic-structural asymmetry between the L and M-branches. However, because of the limited reliability of the semiempirical calculations, it is necessary to perform more reliable ab initio calculations to elucidate the mechanism and the underlying origin of this ET reactions.

In our laboratory, we have developed SAC(symmetryadapted-cluster $)^{12} / \mathrm{SAC}-\mathrm{CI}$ (configuration interaction) ${ }^{13}$ method as a reliable tool to study molecules in the ground, excited, ionized, and electron-attached states. The accuracy of the method had well been examined ${ }^{14}$ through the applications of it to many different fields of chemistry and chemical physics. ${ }^{15,16}$ The method is simple enough to be useful and simple enough to be reliable and therefore applicable even to relatively large biological molecules in a good accuracy. ${ }^{16-22}$ This method has been successfully applied to the ground, excited, and ionized states of various porphyrins, and detailed information on the electronic structures of these compounds was obtained. ${ }^{16-22}$

In the preceding paper $^{23}$ and in the previous communication, ${ }^{24}$ we have described the excitation spectrum of the PSRC of Rps. 


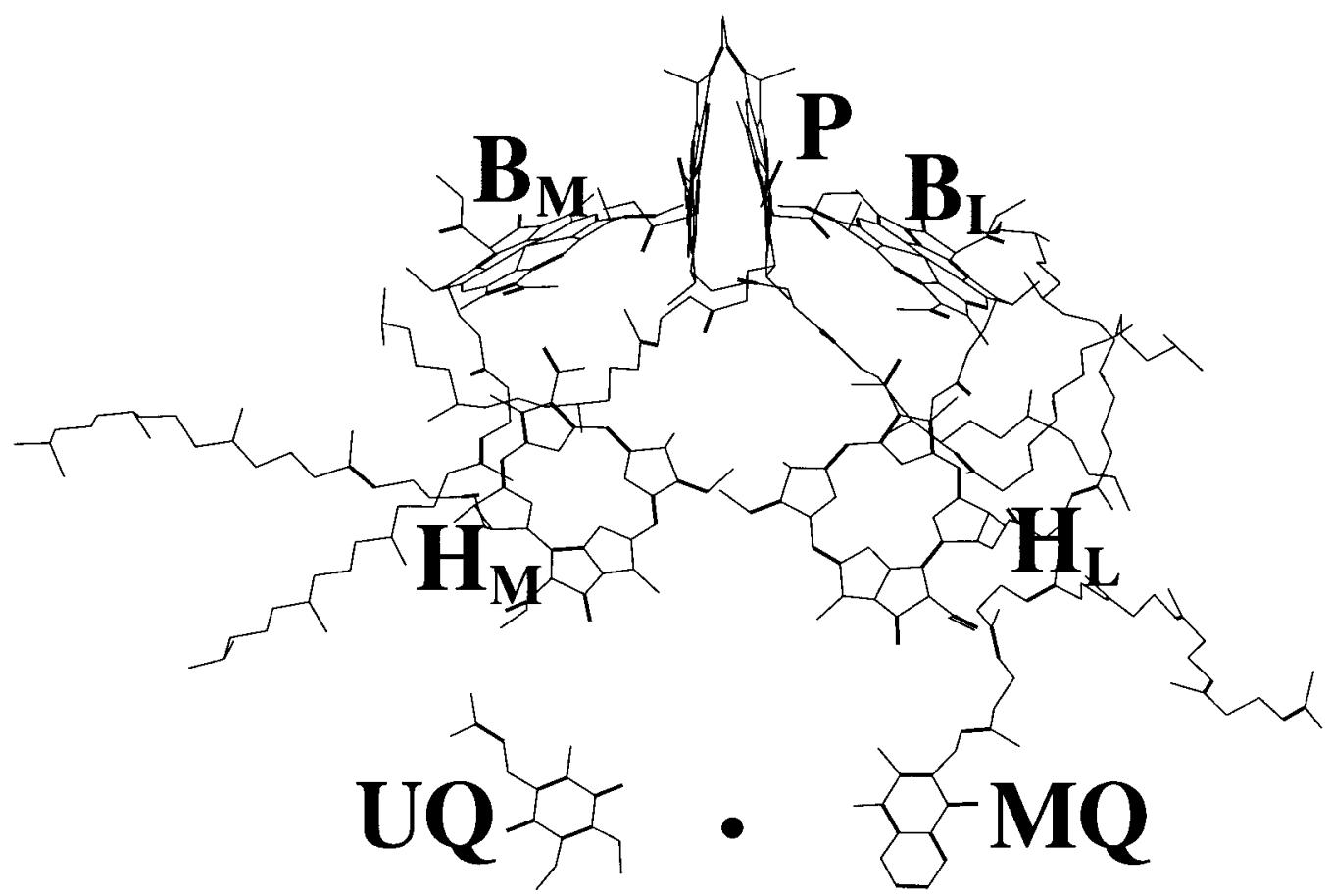

Figure 1. Structure of the chromophores in the photosynthetic reaction center of Rps. viridis. The nuclear coordinates are taken from ref 2.

viridis $^{1}$ by the SAC/SAC-CI method to give a definitive assignment of the spectrum. We have calculated the ground and excited states of all the chromophores in the PSRC of Rps. viridis, $\mathrm{P}, \mathrm{B}_{\mathrm{L}}, \mathrm{B}_{\mathrm{M}}, \mathrm{H}_{\mathrm{L}}, \mathrm{H}_{\mathrm{M}}, \mathrm{MQ}, \mathrm{UQ}$, and four different hemes, c-552, c-554, c-556, and c-559 in the environment of the proteins replaced by an electrostatic model. We could be able to give the assignment of all the peaks within about $1 \mathrm{eV}$ from 1.25 to $2.5 \mathrm{eV}$. We could reproduce not only the ordinary excitation spectrum but also the linear dichroism data. ${ }^{25}$ This calculation was by far the largest calculation so far made by the ab initio theoretical method including large amounts of electron correlations. It gave a firm basis for future photochemical studies of the PSRC of Rps. viridis.

In this paper, we apply the SAC/SAC-CI method to study the electronic mechanism and the origin of the unidirectionality of the ET in the PSRC of Rps. viridis. Since this ET involves many different electronic states of the chromophores in the PSRC, the underlying theoretical method should be reliable for all the states involved. The SAC/SAC-CI method is indeed very suitable to this type of study. The analysis of the calculated results would provide us a basic picture of the ET reactions and its unidirectionality. Further, based on such a picture, we would be able to propose an interesting mutant system for further understanding and development of PSRC: we call such a design a theoretical mutation which is a basis for an effective future collaboration between theoretical and experimental biochemists. A short communication of the present study has been published elesewhere. $^{24}$

In the next section, the calculational details are described. The analyses of the unidirectionality and the efficiency based on the transfer integrals calculated by the SAC/SAC-CI wave functions are then described and a summary and concluding remarks are given in the last section.

\section{Calculation of Transfer Integrals}

We first explain the method of calculations of the transfer integrals using the SAC/SAC-CI wave functions of the chromophores, since this would clarify our basic approximations adopted in the present study. We first take up the electrontransfer process from $\mathrm{P}^{*} \mathrm{~B}$ to $\mathrm{P}^{+} \mathrm{B}^{-}$. The $\mathrm{SAC}$ and $\mathrm{SAC}-\mathrm{CI}$ wave functions of $\mathrm{P}^{*}, \mathrm{P}^{+}, \mathrm{B}$, and $\mathrm{B}^{-}$are expressed as

$$
\begin{aligned}
& \mathrm{P}^{*}: \quad \Psi_{\mathrm{EX}}^{\mathrm{P}}=R^{\mathrm{P}} \exp \left(S^{\mathrm{P}}\right) \Phi_{0}^{\mathrm{P}} \\
& \mathrm{P}^{+}: \quad \Psi_{\mathrm{I}}^{\mathrm{P}}=I^{\mathrm{P}} \exp \left(S^{\mathrm{P}}\right) \Phi_{0}^{\mathrm{P}} \\
& \mathrm{B}: \quad \Psi_{\mathrm{G}}^{\mathrm{B}}=\exp \left(S^{\mathrm{B}}\right) \Phi_{0}^{\mathrm{B}} \\
& \mathrm{B}^{-}: \quad \Psi_{\mathrm{EA}}^{\mathrm{B}}=E^{\mathrm{B}} \exp \left(S^{\mathrm{B}}\right) \Phi_{0}^{\mathrm{B}}
\end{aligned}
$$

where $\Phi_{0}^{\mathrm{P}}$ and $\Phi_{0}^{\mathrm{B}}$ represent the Hartree-Fock wave functions for the ground states of $\mathrm{P}$ and $\mathrm{B}$, respectively, namely, $\Phi_{0}^{\mathrm{P}}=\|$ $\phi_{1}^{\mathrm{P}} \phi_{2}^{\mathrm{P}} \cdots \phi_{N_{\mathrm{P}}}^{\mathrm{P}} \|$ and $\Phi_{0}^{\mathrm{B}}=\left\|\phi_{1}^{\mathrm{B}} \phi_{2}^{\mathrm{B}} \cdots \phi_{N_{\mathrm{B}}}^{\mathrm{B}}\right\|$. The operators $R, I$, and $E$ represent the symmetry-adapted singlet excitation, ionization, and electron attachment operators, respectively. $S$ is the symmetry-adapted excitation operator for the ground state. They are actually the sum of the single and double replacement operators. The subscripts, EX, I, G, and EA denote excited, ionized, ground, and electron-attached states, respectively.

The initial and final states of the ET, $\mathrm{P} * \mathrm{~B}$ and $\mathrm{P}^{+} \mathrm{B}^{-}$, respectively, are approximated by the products of the $\mathrm{SAC} /$ $\mathrm{SAC}-\mathrm{CI}$ wave functions of the fragments

$$
\begin{aligned}
\mathrm{P} * \mathrm{~B}: \quad \Psi^{\mathrm{P}^{* \mathrm{~B}}} & \cong \Psi_{\mathrm{EX}}^{\mathrm{P}} \Psi_{\mathrm{G}}^{\mathrm{B}} \\
& =R^{\mathrm{P}} \exp \left(S^{\mathrm{P}}+S^{\mathrm{B}}\right) \Phi_{0}^{\mathrm{P}+\mathrm{B}} \\
\mathrm{P}^{+} \mathrm{B}^{-}: \quad \Psi^{\mathrm{P}^{+} \mathrm{B}^{-}} & \cong \Psi_{\mathrm{I}}^{\mathrm{P}} \Psi_{\mathrm{EA}}^{\mathrm{B}} \\
& =I^{\mathrm{P}} E^{\mathrm{B}} \exp \left(S^{\mathrm{P}}+S^{\mathrm{B}}\right) \Phi_{0}^{\mathrm{P}+\mathrm{B}}
\end{aligned}
$$

where $\Phi_{0}^{\mathrm{P}+\mathrm{B}}=\left\|\phi_{1}^{\mathrm{P}} \phi_{2}^{\mathrm{P}} \cdots \cdot \phi_{N_{\mathrm{P}}}^{\mathrm{P}} \phi_{1}^{\mathrm{B}} \phi_{2}^{\mathrm{B}} \cdots \phi_{N_{\mathrm{B}}}^{\mathrm{B}}\right\|$. The operator $I^{\mathrm{P}} E^{\mathrm{B}}$ 


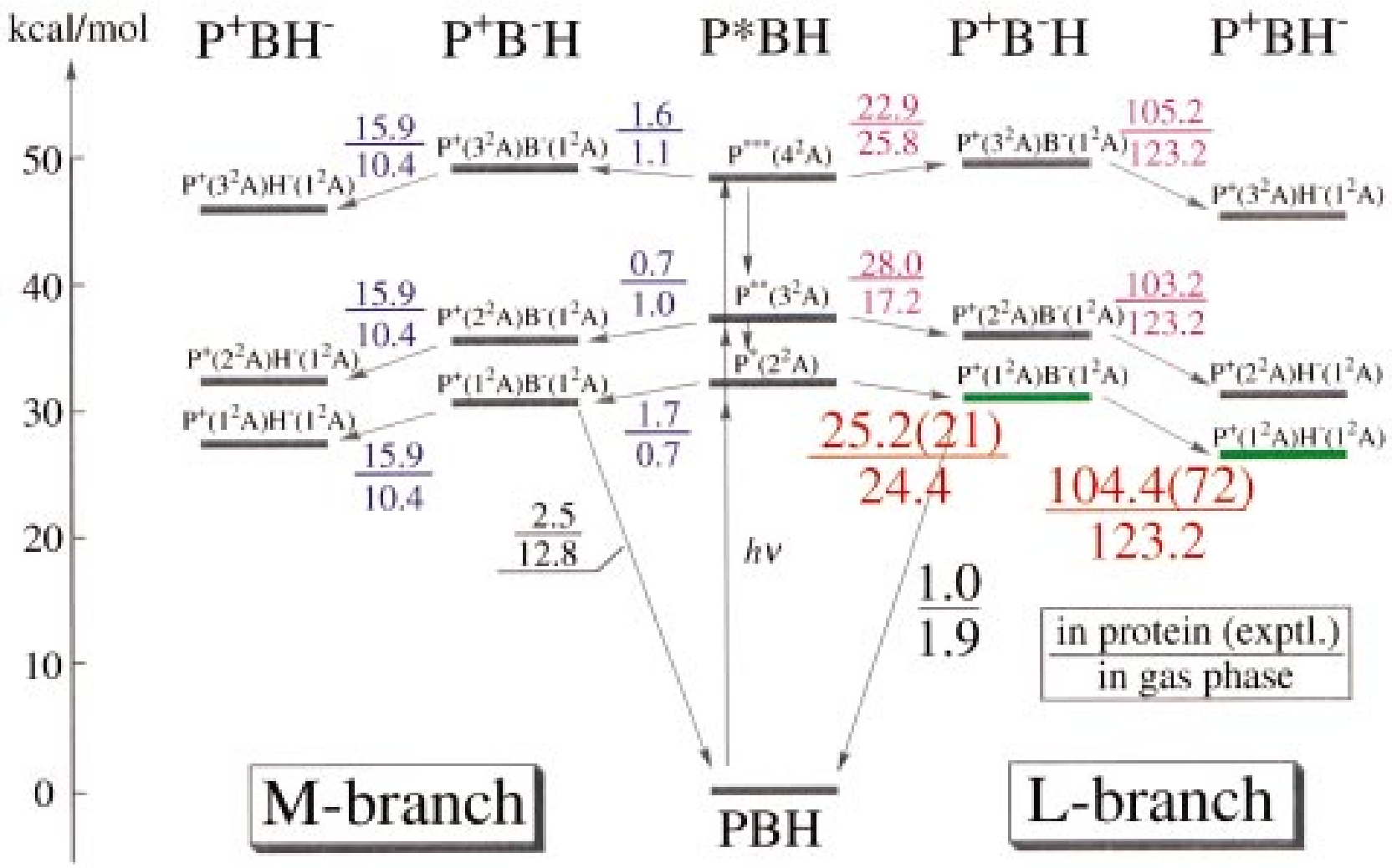

Figure 2. Electronic factors, $\left|H_{\mathrm{IF}}\right|^{2}\left(\times 10^{-9}\right.$ in au) for the electron transfers in the PSRC of Rps. viridis (the upper value is in protein model compared with the experimental value given in the parentheses ${ }^{35}$ and the lower one is in a gas phase). Energy levels colored green are experimentally estimated values ${ }^{37}$ and the black ones calculated by the SAC-CI method.

TABLE 1: Overlap Integrals between the Lower Unoccupied MOs of Special Pair (P) and Bacteriochlorophyll b (B)

\begin{tabular}{|c|c|c|c|}
\hline & \multicolumn{2}{|c|}{$\mathrm{P}$} \\
\hline & & LUMO & LUMO+1 \\
\hline \multicolumn{4}{|c|}{ (1) L-branch } \\
\hline & LUMO & 0.0000052 & -0.0001101 \\
\hline \multirow[t]{2}{*}{ B } & LUMO+1 & 0.0007474 & 0.0004391 \\
\hline & $\mathrm{LUMO}+2$ & 0.0001207 & 0.0001602 \\
\hline \multicolumn{4}{|c|}{ (2) M-branch } \\
\hline \multirow{3}{*}{ B } & LUMO & -0.0000334 & 0.0000856 \\
\hline & LUMO+1 & -0.0003535 & 0.0001162 \\
\hline & LUMO+2 & 0.0001988 & -0.0000987 \\
\hline
\end{tabular}

in eq 2-6 is not symmetry adapted, so that we introduce the operator $R_{\mathrm{I}}^{\mathrm{P}+\mathrm{B}}$ for spin symmetry adaptation.

$$
\mathrm{P}^{+} \mathrm{B}^{-}: \quad \Psi^{\mathrm{P}^{+} \mathrm{B}^{-}}=R^{\mathrm{P}+\mathrm{B}} \exp \left(S^{\mathrm{P}}+S^{\mathrm{B}}\right) \Phi_{0}^{\mathrm{P}+\mathrm{B}} .
$$

The details are given in the appendix.

Finally, the transfer integral of this ET reaction is given by

$$
\mathrm{P}^{*} \mathrm{~B} \text { to } \mathrm{P}^{+} \mathrm{B}^{-}:\left\langle\Psi^{\mathrm{P}^{*} \mathrm{~B}}|H| \Psi^{\mathrm{P}^{+} \mathrm{B}^{-}}\right\rangle
$$

where $H$ is the Hamiltonian of the united system $\mathrm{P}^{+} \mathrm{B}$. Similarly for the next ET reaction, $\mathrm{P}^{+} \mathrm{B}^{-} \mathrm{H}$ to $\mathrm{P}^{+} \mathrm{BH}^{-}$, and for the charge recombination reaction, $\mathrm{P}^{+} \mathrm{B}^{-}$to $\mathrm{PB}$, the transfer integrals are calculated by

$$
\begin{gathered}
\mathrm{P}^{+} \mathrm{B}^{-} \mathrm{H} \text { to } \mathrm{P}^{+} \mathrm{BH}^{-}:\left\langle\Psi^{\mathrm{B}^{-} \mathrm{H}}|\mathrm{H}| \Psi^{\mathrm{BH}^{-}}\right\rangle \\
\mathrm{P}^{+} \mathrm{B}^{-} \text {to } \mathrm{PB}:\left\langle\Psi^{\mathrm{P}^{+} \mathrm{B}^{-}}|\mathrm{H}| \Psi^{\mathrm{PB}}\right\rangle
\end{gathered}
$$

For these processes, we additionally need the following SAC/
$\mathrm{SAC}-\mathrm{CI}$ wave functions

$$
\begin{aligned}
& \text { P: } \quad \Psi_{\mathrm{G}}^{\mathrm{P}}=\exp \left(S^{\mathrm{P}}\right) \Phi_{0}^{\mathrm{P}} \\
& \mathrm{H}: \quad \Psi_{\mathrm{G}}^{\mathrm{H}}=\exp \left(S^{\mathrm{H}}\right) \Phi_{0}^{\mathrm{H}} \\
& \mathrm{H}^{-}: \quad \Psi_{\mathrm{EA}}{ }^{\mathrm{H}}=E^{\mathrm{H}} \exp \left(S^{\mathrm{H}}\right) \Phi_{0}^{\mathrm{H}}
\end{aligned}
$$

The constructions of the product wave functions and the calculations of the transfer integrals are essentially the same as in the above case.

To calculate all the necessary quantities, we use the SAC/ SAC-CI wave functions for $\mathrm{P}_{\mathrm{G}}, \mathrm{P}^{*}, \mathrm{P}^{+}, \mathrm{B}_{\mathrm{G}}(\mathrm{L}), \mathrm{B}_{\mathrm{G}}(\mathrm{M}), \mathrm{B}^{-}(\mathrm{L})$, $\mathrm{B}^{-}(\mathrm{M}), \mathrm{H}_{\mathrm{G}}(\mathrm{L}), \mathrm{H}_{\mathrm{G}}(\mathrm{M}), \mathrm{H}^{-}(\mathrm{L})$ and $\mathrm{H}^{-}(\mathrm{M})$, where $\mathrm{L}$ and $\mathrm{M}$ denote those in the L- and M-branches, respectively. Some of these wave functions have already been calculated in the previous study, ${ }^{23}$ but others have been newly calculate during this study.

In the calculation of transfer integrals, we assume an orthogonality between the MOs of different chromophores, since the calculated overlap integrals were very small as shown in Table 1. The overlap integrals between the lower unoccupied MOs of $\mathrm{P}$ and $\mathrm{B}$ were at most on the order of $10^{-4}$. Further, for the sake of simplicity, we considered only the linked configurations having the coefficients larger than 0.1 in the SAC/ $\mathrm{SAC}-\mathrm{CI}$ wave functions.

\section{Computational Details}

The calculations of the SAC/SAC-CI wave functions for the PSRC of Rps. viridis are explained in some detail in the preceding paper. $^{23}$ The geometries of the chromophores are taken from the X-ray crystallographic data ${ }^{2}$ (1PRC in Brookhaven 


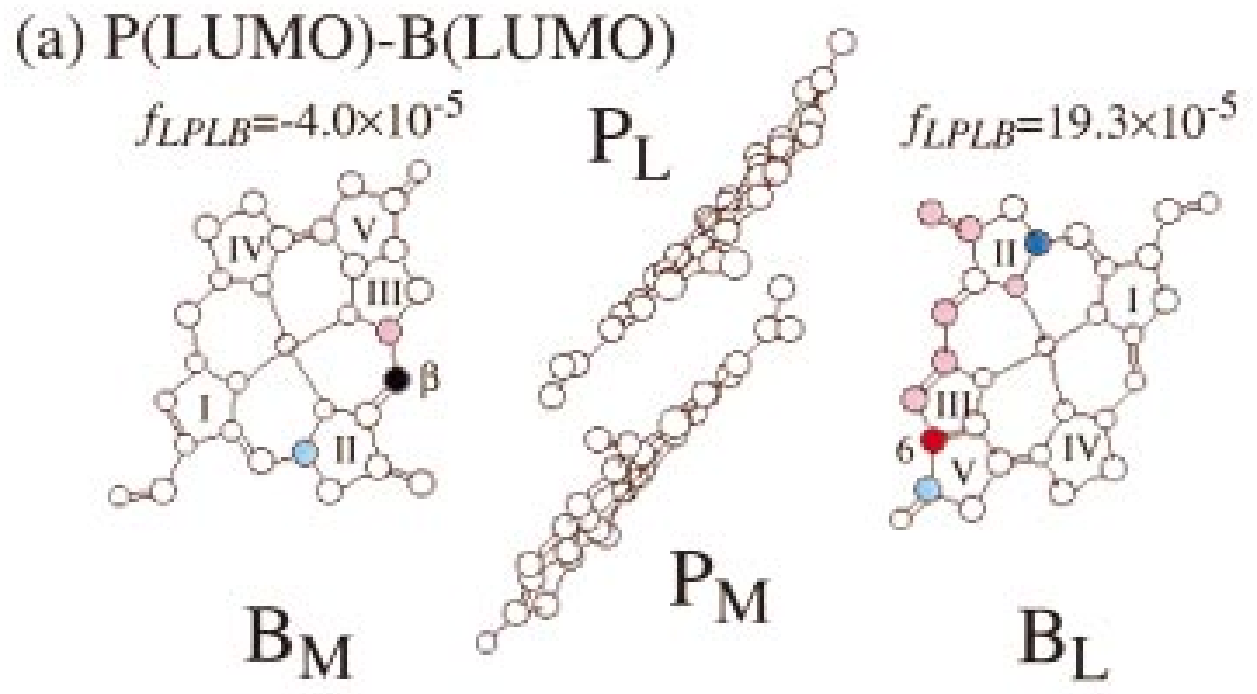

(b) $\mathrm{P}(\mathrm{HOMO})-\mathrm{B}(\mathrm{LUMO})$
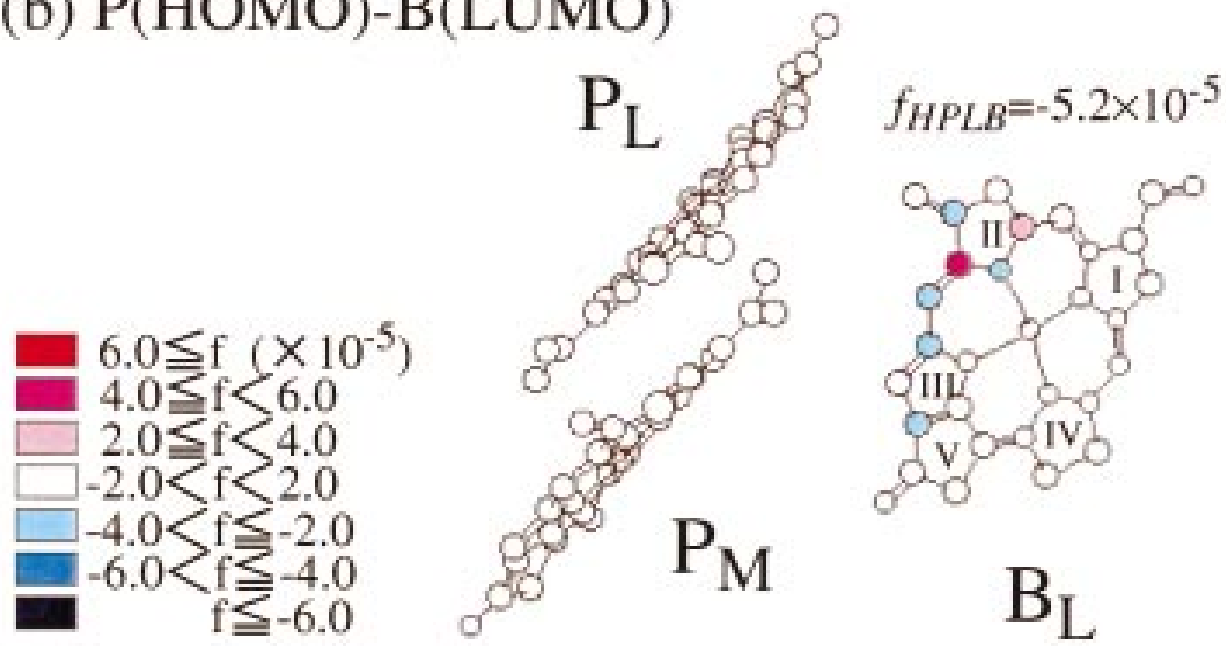

Figure 3. Atomic contributions of $B_{L}$ and $B_{M}$ for the transfer integrals between $\mathrm{P}$ and $\mathrm{B}$ (a) for the electron transfer and (b) for the charge recombination.

Data Bank $^{26}$ ) and were shown in Figure 3 of ref 23 . The labeling of the atoms and rings was also given there. Some branched fragments of the chromophores were simplified except for the ones which may have $\pi$-conjugation with the porphyrin rings. We use Huzinaga's (63/5)/[2s2p] CGTO's for carbon, nitrogen, and oxygen atoms ${ }^{27}$ and (4)/[1s] set ${ }^{28}$ for hydrogen. For $\mathrm{Mg}$, Huzinaga's $(533 / 5) /[5 \mathrm{~s} / 3 \mathrm{p}]$ set $^{27}$ plus two p-type polarization functions $(\xi=0.045$ and 0.143$)$ and d-type polarization functions $(\xi=1.01)$ are used. ${ }^{23}$ Protein effect is introduced by a point-charge model. Namely, the charges reported previously ${ }^{29,30}$ for proteins and waters and the HartreeFock populations for the other chromophores which are obtained by the present and previous ${ }^{23}$ calculations are placed at the centers of the respective atoms. ${ }^{2}$

The SAC/SAC-CI wave functions for the ground and excited states of all the chromophores are the same as those calculated in the previous spectroscopic studies of the PSRC. ${ }^{23}$ For the ionized and electron-attached states, additional SAC-CI calculations are performed similarly to the previous case. ${ }^{23}$ At least 2 p-electrons are correlated in the active space and the perturbation selection ${ }^{17,31}$ is carried out for the double excitation operators. For the electron attached states of $\mathrm{B}$ and $\mathrm{H}$, the energy threshold $1 \times 10^{-6}$ au is used and for the ionized states of $\mathrm{P}$, the threshold $3 \times 10^{-6}$ au is used. All single excitations and the selected double excitations are included in the linked term. For the Hartree-Fock SCF calculation, the HONDO version 8 program, ${ }^{32}$ and for the SAC/SAC-CI calculation, the updated version ${ }^{33}$ of SAC 85 program, ${ }^{34}$ was used.

\section{Examination of the Electron Transfer and Charge Recombination Processes}

We present the squares of the calculated transfer integrals $\left|H_{\mathrm{IF}}\right|^{2}$ (hereafter, we call this value just transfer integral and the unit is $1.0 \times 10^{-9} \mathrm{au}$ ) for the ET process from $\mathrm{P}^{*} \mathrm{~B}$ to $\mathrm{P}^{+} \mathrm{B}^{-}$ in Table 2 and for the ET process from $\mathrm{P}^{+} \mathrm{B}^{-} \mathrm{H}$ to $\mathrm{P}^{+} \mathrm{BH}^{-}$in Table 3. Table 2 also gives the transfer integrals for the charge recombination process $\mathrm{P}^{+} \mathrm{B}^{-}$to $\mathrm{PB}$. These are the values between many lower states of the system and include the effects of proteins in an electrostatic point-charge model.

The most relevant values in Table 2 for the ET process under study are those from the lowest excited state of $\mathrm{P}, \mathrm{P}^{*}\left(2^{1} \mathrm{~A}\right) \mathrm{B}$ to the lowest ion-pair states, $\mathrm{P}^{+}\left(1^{2} \mathrm{~A}\right) \mathrm{B}^{-}\left(1^{2} \mathrm{~A}\right)$ in the $\mathrm{L}-$ and M-branches, which are 25.21 and 1.65 , respectively. The transfer integral for the L-branch is much larger than the one for the M-branch. We also calculated the transfer integrals from 
TABLE 2: Square of the Transfer Integrals $\left|H_{\mathrm{IF}}\right|^{2}$ for the Electron Transter and the Charge Recombination between Special Pair (P) and Bacteriochlorophylls $b(\mathrm{~B})\left(\times 10^{-9}\right.$ au $)$

\begin{tabular}{|c|c|c|c|c|c|}
\hline & $\mathrm{P}\left(\mathrm{X}^{1} \mathrm{~A}\right) \mathrm{B}$ & $\mathrm{P} *\left(2^{1} \mathrm{~A}\right) \mathrm{B}$ & $\mathrm{P} *\left(3^{1} \mathrm{~A}\right) \mathrm{B}$ & $\mathrm{P} *\left(4^{1} \mathrm{~A}\right) \mathrm{B}$ & $\mathrm{P}^{*}\left(5^{1} \mathrm{~A}\right) \mathrm{B}$ \\
\hline \multicolumn{6}{|l|}{ (1) L-branch } \\
\hline $\mathrm{P}^{+}\left(1^{2} \mathrm{~A}\right) \mathrm{B}^{-}\left(1^{2} \mathrm{~A}\right)$ & 0.96 & 25.21 & 0.13 & 0.18 & 5.74 \\
\hline $\mathrm{P}^{+}\left(2^{2} \mathrm{~A}\right) \mathrm{B}^{-}\left(1^{2} \mathrm{~A}\right)$ & 0.06 & 0.14 & 28.04 & 0.01 & 2.49 \\
\hline $\mathrm{P}^{+}\left(3^{2} \mathrm{~A}\right) \mathrm{B}^{-}\left(1^{2} \mathrm{~A}\right)$ & 51.16 & 0.20 & 0.17 & 22.94 & 0.10 \\
\hline $\mathrm{P}^{+}\left(1^{2} \mathrm{~A}\right) \mathrm{B}^{-}\left(2^{2} \mathrm{~A}\right)$ & 6.73 & 15.16 & 0.04 & 0.17 & 3.88 \\
\hline $\mathrm{P}^{+}\left(2^{2} \mathrm{~A}\right) \mathrm{B}^{-}\left(2^{2} \mathrm{~A}\right)$ & 12.64 & 0.00 & 16.22 & 0.00 & 1.04 \\
\hline $\mathrm{P}^{+}\left(3^{2} \mathrm{~A}\right) \mathrm{B}^{-}\left(2^{2} \mathrm{~A}\right)$ & 101.45 & 0.94 & 0.02 & 11.66 & 0.01 \\
\hline \multicolumn{6}{|l|}{ (2) M-branch } \\
\hline $\mathrm{P}^{+}\left(1^{2} \mathrm{~A}\right) \mathrm{B}^{-}\left(1^{2} \mathrm{~A}\right)$ & 2.54 & 1.65 & 0.16 & 0.28 & 0.74 \\
\hline $\mathrm{P}^{+}\left(2^{2} \mathrm{~A}\right) \mathrm{B}^{-}\left(1^{2} \mathrm{~A}\right)$ & 16.98 & 0.06 & 0.67 & 0.00 & 0.01 \\
\hline $\mathrm{P}^{+}\left(3^{2} \mathrm{~A}\right) \mathrm{B}^{-}\left(1^{2} \mathrm{~A}\right)$ & 2.29 & 0.14 & 0.15 & 1.58 & 0.11 \\
\hline $\mathrm{P}^{+}\left(1^{2} \mathrm{~A}\right) \mathrm{B}^{-}\left(2^{2} \mathrm{~A}\right)$ & 19.26 & 10.40 & 0.24 & 0.68 & 0.61 \\
\hline $\mathrm{P}^{+}\left(2^{2} \mathrm{~A}\right) \mathrm{B}^{-}\left(2^{2} \mathrm{~A}\right)$ & 61.09 & 0.53 & 8.42 & 0.00 & 0.41 \\
\hline $\mathrm{P}^{+}\left(3^{2} \mathrm{~A}\right) \mathrm{B}^{-}\left(2^{2} \mathrm{~A}\right)$ & 0.78 & 0.11 & 0.20 & 12.48 & 0.13 \\
\hline
\end{tabular}

TABLE 3: Square of the Transfer Integrals $\left|H_{\mathrm{IF}}\right|^{2}$ for the Electron Transter between Bacteriochlorophylls $b$ (B) and Bacteriopheophytins $(\mathrm{H})\left(\times 10^{-9}\right.$ au $)$

\begin{tabular}{crrr}
\hline & $\mathrm{B}^{-}\left(1^{2} \mathrm{~A}\right)$ & $\mathrm{B}^{-}\left(2^{2} \mathrm{~A}\right)$ & $\mathrm{B}^{-}\left(3^{2} \mathrm{~A}\right)$ \\
\hline (1) L-branch & & & \\
$\mathrm{H}^{-}\left(1^{2} \mathrm{~A}\right)$ & 104.43 & 1.99 & 36.50 \\
$\mathrm{H}^{-}\left(2^{2} \mathrm{~A}\right)$ & 0.95 & 0.71 & 28.68 \\
$\mathrm{H}^{-}\left(3^{2} \mathrm{~A}\right)$ & 134.93 & 2.46 & 227.62 \\
$(2) \mathrm{M}-$ branch & & & \\
$\mathrm{H}^{-}\left(1^{2} \mathrm{~A}\right)$ & 15.93 & 54.41 & 65.38 \\
$\mathrm{H}^{-}\left(2^{2} \mathrm{~A}\right)$ & 6.72 & 5.18 & 4.21 \\
$\mathrm{H}^{-}\left(3^{2} \mathrm{~A}\right)$ & 4.32 & 47.72 & 61.73
\end{tabular}

higher excited states of $\mathrm{P} *$ to many different electronic states of $\mathrm{P}^{+} \mathrm{B}^{-}$. Again the L-branch values are generally larger than the M-branch values, though the reality of these ET routes is limited, as discussed in the next section.

The first column of Table 2 gives the transfer integrals for the charge recombination processes from $\mathrm{P}^{+} \mathrm{B}^{-}$to $\mathrm{PB}$. The most relevant value is 0.96 from the lowest state of $\mathrm{P}^{+} \mathrm{B}^{-}$in the L-branch to the lowest state of PB: it is much smaller than the value for the ET, 25.21 for $\mathrm{P}^{*}\left(2^{1} \mathrm{~A}\right) \mathrm{B}$ to $\mathrm{P}^{+} \mathrm{B}^{-}$. The corresponding value for the $\mathrm{M}$-branch is 2.54 , again very small.

The transfer integral for the succeeding ET process, $\mathrm{P}^{+} \mathrm{B}^{-} \mathrm{H}$ to $\mathrm{P}^{+} \mathrm{BH}^{-}$, is 104.43 for the L-branch and 15.93 for the M-branch as seen from Table 3. Again, the L-branch ET has much wider route than the M-branch one. Though the values for the processes involving the excited states of $\mathrm{B}^{-}$or $\mathrm{H}^{-}$are also given in Table 3, they are less important for the present purpose.

Thus, the result of the calculated transfer integrals reproduces the L-branch selectivity in the sequential ET process, $\mathrm{P} * \mathrm{BH} \rightarrow$ $\mathrm{P}^{+} \mathrm{B}^{-} \mathrm{H} \rightarrow \mathrm{P}^{+} \mathrm{BH}^{-}$. It also shows a low probability of the occurrence of the charge recombination, $\mathrm{P}^{+} \mathrm{B}^{-} \mathrm{H}$ to $\mathrm{PBH}$. The calculated transfer integrals for the L-branch, 25.21 for $\mathrm{P} * \mathrm{BH}$ to $\mathrm{P}^{+} \mathrm{B}^{-} \mathrm{H}$ and 104.43 for $\mathrm{P}^{+} \mathrm{B}^{-} \mathrm{H}$ to $\mathrm{P}^{+} \mathrm{BH}^{-}$, are both in good agreement with the experimentally estimated values 21 and 72 , respectively. ${ }^{35}$ These results are quite encouraging and seem to suggest that the L-branch selectivity and a high charge separation yield (low charge recombination process) of the ET in the PSRC of Rps. viridis are controlled by the transfer integral, i.e., the electronic factor in the Marcus formula.

To obtain a better understanding on the implications of the Marcus formula, we tried to estimate the energy levels of the electron-transfer pathway in the PSRC of Rps. viridis. This information is related with the thermodynamic factor in the Marcus formula.

The energy of the electron transferred state relative to the neutral ground state may be calculated as

$E_{\mathrm{ET}}=\mathrm{IP}-\mathrm{EA}+E(+-)+\operatorname{relax}($ chromophore $)+$ relax(protein) (4-1)
TABLE 4: Estimation of the Energy Levels of the Electron Transfer Pathway

\begin{tabular}{|c|c|c|c|c|c|}
\hline \multirow{2}{*}{$\begin{array}{c}\text { energy } \\
\text { contribution }^{a}\end{array}$} & \multirow[b]{2}{*}{$\mathrm{P}^{*}$} & \multicolumn{2}{|c|}{$\mathrm{P}^{+} \mathrm{B}^{-}$} & \multicolumn{2}{|c|}{$\mathrm{P}^{+} \mathrm{H}^{-}$} \\
\hline & & $\mathrm{M}$ & $\mathrm{L}$ & $\mathrm{M}$ & $\mathrm{L}$ \\
\hline \multicolumn{6}{|c|}{ In Gas Phase } \\
\hline$\Delta E$ or IP-EA ${ }^{b}$ & 1.42 & 4.41 & 4.45 & 4.66 & 4.60 \\
\hline $\begin{array}{l}E(+-) \\
\operatorname{relax}(\mathrm{c})\end{array}$ & 0.00 & -1.34 & -1.49 & -0.83 & -0.85 \\
\hline $\operatorname{relax}(\mathrm{p})^{c}$ & 0.00 & -0.5 & -0.5 & -0.9 & -0.9 \\
\hline total & 1.42 & 2.57 & 2.46 & 2.93 & 2.85 \\
\hline$\Delta$ & 0.00 & 1.15 & 1.04 & 1.51 & 1.43 \\
\hline \multicolumn{6}{|c|}{ In Protein } \\
\hline$E(+-)$ & 0.00 & -1.26 & -1.50 & -0.71 & -0.95 \\
\hline $\operatorname{relax}(\mathrm{c})$ & & & & & \\
\hline $\operatorname{relax}(\mathrm{p})^{c}$ & 0.00 & -0.5 & -0.5 & -0.9 & -0.9 \\
\hline total & 1.41 & 3.05 & 3.35 & 1.41 & 3.72 \\
\hline$\Delta$ & 0.00 & 1.64 & 1.94 & 0.00 & 2.31 \\
\hline$\Delta(\operatorname{exptl})$ & 0.00 & & -0.09 & & -0.25 \\
\hline
\end{tabular}

${ }^{a}$ Detailed accounts are given in the text. ${ }^{b}$ Estimated by the SACCI method ${ }^{c}$ The value estimated by Thompson and Zerner. ${ }^{6}$

where IP is the ionization potential of $\mathrm{P}, \mathrm{EA}$ the electron affinity of $\mathrm{B}$ or $\mathrm{H}, E(+-)$ the Coulombic interaction energy between the donor $\mathrm{P}^{+}$and the acceptor $\mathrm{B}^{-}$or $\mathrm{H}^{-}, \operatorname{relax}($ chromophore) the relaxation energy of the chromophore, and relax(protein) the relaxation energy of proteins and the surrounding medium. The first two terms, IP-EA are rather easily calculated, at least the vertical values, by the SAC-CI method. The term $E(+-)$ is calculated as a sum of the Coulombic interaction energies between the gross charges of the donor and acceptor. The relaxation energy of the chromophore, relax(chromophore), in the environment of proteins and waters is rather difficult to calculate, though the relaxation energy in a gas phase is calculated within the scope of the SAC-CI method with the use of the gradient technique recently established. ${ }^{36}$ The relaxation energy of the protein medium is difficult to estimate by the present $a b$ initio method. Actually, the terms in eq 4-1 couple to each other and this coupling may be essential.

Table 4 shows the estimated energy levels of the electron transferred state. $\Delta E$ which is the excitation energy of $\mathrm{P}$ and the values of $\mathrm{IP}-\mathrm{EA}$ for $\mathrm{P}^{+} \mathrm{B}^{-}$and $\mathrm{P}^{+} \mathrm{H}^{-}$are calculated by the SAC-CI method with and without the electrostatic field due to the proteins and waters. The value of $E(+-)$ is estimated by the above approximation. The relaxation energy, relax(chromophore), was not estimated. For relax(protein), we used the values estimated by Thompson and Zerner ${ }^{6}$ based on the continuum reaction-field model. The upper half shows the result for a gas phase and the lower half the results in proteins. The value relative to the energy level of $\mathrm{P}^{*}, \Delta$, is given in the bottom and compared with the experimentally estimated values for the L-branch ${ }^{37}$ given in the extreme bottom row. Unfortunately, 
the present estimated $\Delta$ values are by far different from the experimentally estimated values. This is perhaps due to the poor or no estimation of the relaxation energies of chromophores and protein medium. A proper estimation of these relaxation energies is certainly very important, but at present, we have to abandon it for a luck of sufficient knowledge and methodology. Then, we decided to use the experimentally estimated values of $\Delta$ when necessary.

\section{Unidirectionality of the ET and Its Effectiveness}

We present here a view on the mechanism of the unidirectionality and the effectiveness of the ET in the PSRC of Rps. viridis on the basis of the $\mathrm{SAC}-\mathrm{CI}$ data presented in the preceding section. Figure 2 shows a summary of the present results pertinent for the succeeding discussions. It shows the calculated transfer integrals, $\left|H_{\mathrm{IF}}\right|^{2}$, in proteins and in a gas phase for each process. The values in parentheses are those estimated from the experimental data. ${ }^{35}$ They are proportional to the ET rate constant as seen from the Marcus formula given in eq 1-1. Only the electronic factors larger than 1.00 are shown. The energy levels of the two lower states in the L-branch colored green are the experimentally estimated values, ${ }^{37}$ but for others, we use the SAC-CI values calculated from the excitation energies, ionization energies, and electron affinities. The theoretical transfer integrals (including protein effect) for the ETs from $\mathrm{P}$ to $\mathrm{B}$ and from $\mathrm{B}$ to $\mathrm{H}$ are 25.2 and 104.4, respectively, which are in good agreement with the experimentally estimated values, 21 and 72, respectively. It indicates the adequacy of the present theoretical method.

Thus, the ET reaction from $\mathrm{P}$ to $\mathrm{H}$ is described as follows based on the data summarized in Figure 2. First, the excitation of $\mathrm{P}$ occurs by a direct photoexcitation or by an energy transfer from antenna molecule, ${ }^{1}$ and it would be relaxed to the first excited state, $\mathrm{P}^{*}\left(2^{1} \mathrm{~A}\right)$, by an internal conversion as described by Kasha's rule. The ET from $\mathrm{P}$ to $\mathrm{B}$, i.e., from $\mathrm{P}\left(2^{1} \mathrm{~A}\right)$ to $\mathrm{P}^{+}\left(1^{2} \mathrm{~A}\right) \mathrm{B}^{-}\left(1^{2} \mathrm{~A}\right)$, would occur along the L-branch, since the electronic factor of the L-side is about 15 times larger than that of the M-side as shown in Figure 2. This electron transfer occurs mainly from the LUMO of $\mathrm{P}$ to the LUMO of $\mathrm{B}_{\mathrm{L}}$. The unidirectionality is originated from the asymmetry of the transfer integral: the calculated branching ratio $\left|H_{\mathrm{L}}\right|^{2} /\left|H_{\mathrm{M}}\right|^{2} \cong 15$ in proteins $\left(\left.\left|H_{\mathrm{L}}{ }^{2} /\right| H_{\mathrm{M}}\right|^{2} \cong 35\right.$ in a gas phase) is large enough to explain the experimental branching ratio $k_{\mathrm{L}} / k_{\mathrm{M}}>5 .{ }^{8}$ Here, the above consideration is based on the sequential mechanism, since the energy of the intermediate radical pair, $\mathrm{P}^{+} \mathrm{B}^{-}$, was experimentally estimated to be lower than that of the $\mathrm{P}^{*}$ state. ${ }^{37,38}$ Even if the ET occurs faster than the Kasha's internal conversion within $\mathrm{P}$, the $\mathrm{L}$-side is also preferable to the $\mathrm{M}$-side, since the transfer integrals between the higher nearby states of $\mathrm{P}^{*}$ and $\mathrm{B}$ (actually from $\mathrm{P}^{* *}\left(3^{2} \mathrm{~A}\right)$ to $\mathrm{P}^{+}\left(2^{2} \mathrm{~A}\right) \mathrm{B}^{-}\left(1^{2} \mathrm{~A}\right)$ and from $\mathrm{P}^{* * *}\left(4^{2}\right.$ A) to $\left.\mathrm{P}^{+}\left(3^{2} \mathrm{~A}\right) \mathrm{B}^{-}\left(1^{2} \mathrm{~A}\right)\right)$ are larger on the $\mathrm{L}$-side than on the $\mathrm{M}$-side (see Figure 2).

A competitive reaction to the ET from $\mathrm{B}$ to $\mathrm{H}$ is the $\mathrm{CR}$ reaction from $\mathrm{P}^{+} \mathrm{B}^{-} \mathrm{H}$ to the ground state of $\mathrm{PBH}$. This $\mathrm{CR}$ is a transfer of an electron from $\operatorname{LUMO}\left(\mathrm{B}_{\mathrm{L}}\right)$ to $\operatorname{HOMO}(\mathrm{P})$. The transfer integral for the ET from B to $\mathrm{H}$ is 104.4 which is much larger than that for the $\mathrm{CR} 1.0$, so that the $\mathrm{CR}$ is much less preferable to the ET: the branching ratio here to the CR is 1.0/ 104.4 , about $1 \%$ of that of the ET, which agrees reasonably well with the so-called efficiency (quantum yield) of the photosynthesis.

The successive ET from $\mathrm{P}^{+}\left(1^{2} \mathrm{~A}\right) \mathrm{B}^{-}\left(1^{2} \mathrm{~A}\right)$ to $\mathrm{P}^{+}\left(1^{2} \mathrm{~A}\right) \mathrm{H}^{-}\left(1^{2} \mathrm{~A}\right)$ proceeds along the L-branch. This transfer occurs mainly from
$\operatorname{LUMO}\left(\mathrm{B}_{\mathrm{L}}\right)$ to $\operatorname{LUMO}\left(\mathrm{H}_{\mathrm{L}}\right)$. Further, we note that even if the electron transfer from $\mathrm{B}$ to $\mathrm{H}$ might occur through higher electronic states, the transfer integrals themselves are large enough to permit such processes. From Figure 2 we see that the transfer integrals between the second and third higher states of $\mathrm{P}^{+} \mathrm{B}^{-} \mathrm{H}$ and $\mathrm{P}^{+} \mathrm{BH}^{-}$are again very large in the L-branch in contrast to the corresponding values in the M-branch, though such higher electronic processes should scarcely occur for the Kasha's rule.

After the ET to $\mathrm{H}$, the electron is known to be transferred further to MQ. ${ }^{1}$ This process (200 ps) occurs slower by about 2 orders of magnitude than the ET from $\mathrm{P}^{*}$ to $\mathrm{H}$ ( $3 \mathrm{ps)}$ and will be studied separately. The side reaction of the ET to MQ is the CR to the ground state, PBH. The electronic factor of the ET to MQ was reported to be 0.48 in the previous article. ${ }^{39} \mathrm{On}$ the other hand, the electronic factor of the CR reaction by the superexchange mechanism is evaluated to be $0.053,{ }^{40}$ which is small enough to explain the high efficiency of the ET from $\mathrm{H}$ to $\mathrm{MQ}$.

The ET process from MQ to UB is a very slow process (100 ns), and therefore, many other factors such as relaxations and vibrations may couple with the process. The nature of the process may therefore be different from that studied here and will be studied in the forthcoming paper.

\section{Effect of Proteins on the Transfer Integrals}

The roles of proteins in the ET reactions in the PSRC may be classified into three types: (1) The static and dynamic structural factors (The proteins hold the chromophores in the three-dimensional arrays and vibrate together. The resultant most probable geometries are understood as those reported by the X-ray crystallography.), (2) the electrostatic effect on the electronic structures of the chromophores, and (3) the electronic factors through protein wave functions. Though factor 2 can be included into factor 3 , we consider each separately.

The structural factor, the static one in particular, is definitively the most important one. As clearly shown in the succeeding sections, the efficient ET mechanism and the unidirectionality owe their origin to the three-dimensional effective array of the chromophores and its asymmetry between the L- and Mbranches.

On the other hand, the electrostatic effect of proteins, which is taken into account by the point charge model, is small. In Figure 2, the transfer integrals shown in the numerator were calculated including the protein point-charge effect, while those shown in the denominator do not include such an effect, i.e., were calculated in a gas phase. These two values are close: the effectiveness of the ET and the unidirectionality could be explained without introducing the protein electrostatic effect. Table 4 shows the protein electrostatic effect on the energy levels of the chromophores. They are not small, but it is difficult at present to estimate its role in the ET process in the PSRC, though some authors believe it to be important.

The electronic factors of proteins through their electronic wave functions are difficult to estimate, at present, especially from ab initio theoretical point of view. Particularly, there may be another ET pathways through protein electronic states in a superexchange mechanism. However, we believe such possibility is small, at least for the ET from $\mathrm{P}^{*}$ to $\mathrm{H}$, since it occurs within $3 \times 10^{-12} \mathrm{~s}$, very fast, and since the density of the proteins in this region of the PSRC is small. Further, the LUMOs of the B's and H's involved are much lower than those 
TABLE 5: Electronic Factors $\left|H_{\mathrm{IF}}\right|^{2}\left(\times 10^{-9}\right.$ au $)$ in au with Some Approximations ${ }^{a}$

\begin{tabular}{|c|c|c|c|c|c|c|}
\hline \multirow[b]{2}{*}{ approximation } & \multicolumn{3}{|c|}{$\mathrm{P}^{*} \rightarrow \mathrm{B}$} & \multicolumn{3}{|c|}{$\mathrm{B}^{-} \rightarrow \mathrm{H}$} \\
\hline & $\mathrm{L}$ & M & $\mathrm{L} / \mathrm{M}$ & $\mathrm{L}$ & M & $\mathrm{L} / \mathrm{M}$ \\
\hline \multicolumn{7}{|c|}{ Single-Configuration Approximation } \\
\hline$F^{b}$ & 37.36 & 1.83 & 20.42 & 116.96 & 17.96 & 6.51 \\
\hline$H^{c}$ & 37.13 & 1.85 & 20.07 & 116.96 & 17.96 & 6.51 \\
\hline \multicolumn{7}{|c|}{ Multiconfiguration } \\
\hline $\mathrm{SAC}-\mathrm{CI}$ & 25.21 & 1.65 & 15.27 & 104.43 & 15.93 & 6.56 \\
\hline \multicolumn{7}{|c|}{ Experimentally Estimated Values } \\
\hline
\end{tabular}

${ }^{a}$ Calculated with the point-charge protein model. ${ }^{b}$ Fock approximation for total Hamiltonian. ${ }^{c}$ Total Hamiltonian. ${ }^{d}$ Reference 35. ${ }^{e}$ Reference 41 .

of the amino acid residues of proteins, and their HOMOs are again higher than those of the proteins. Adequate HOMOLUMO gaps of the chromophores hinder other electronic processes and makes the overall quantum yield of charge separation very high.

On the other hand, for the ETs from $\mathrm{H}$ to $\mathrm{MQ}$ and in particular, from MQ to UQ, the protein wave functions and probably its dynamic effects would be important. We expect an existence of the ET route due to the superexchange mechanism involving the lower excited states of proteins.

\section{Analysis of the Transfer Integrals}

We now analyze the transfer integrals in some detail to elucidate the origins of the efficient ET mechanism and the unidirectionality. For this purpose, we need a convenient method of analysis of the transfer integrals defined by eqs 2-72-9. Table 5 shows various approximations of the electronic factors, $\left|H_{\mathrm{IF}}\right|^{2}$, for the ET from $\mathrm{P}^{*} \mathrm{~B}$ to $\mathrm{P}^{+} \mathrm{B}^{-}$and from $\mathrm{P}^{+} \mathrm{B}^{-} \mathrm{H}$ to $\mathrm{P}^{+} \mathrm{BH}^{-}$. The first two rows show the values due to the singleconfiguration approximation: in the upper one, the total Hamiltonian was replaced with the Fock operator and in the second one the total Hamiltonian was used. We see that the Fock approximation is very good for this system. However, the single-configuration approximation is not necessarily a good approximation as seen in Table 5: an inclusion of the configuration interaction effect by the $\mathrm{SAC} / \mathrm{SAC}-\mathrm{CI}$ method reduces the transfer integrals and makes them closer to the experimentally estimated values. ${ }^{35}$ The ratios between the values for the $\mathrm{L}-$ and $\mathrm{M}$-branches are also shown in Table 5. For the ET from $\mathrm{P} * \mathrm{~B}$ to $\mathrm{P}^{+} \mathrm{B}^{-}$, the $\mathrm{SAC}-\mathrm{CI}$ method reduces the $\mathrm{L} / \mathrm{M}$ ratio by $3 / 4$. Thus, while the Fock approximation appears somehow qualitative, it is clear that it describes well the dominant term of the transfer integral, and therefore, we will use this approximation for the analysis of the transfer integrals.

A. Factor for the ET from $\mathbf{P}$ to $\mathbf{B}$. The unidirectionality of the ET in the PSRC of Rps. viridis originates from the asymmetry of the transfer integrals between the L- and Mbranches as shown in Figure 2. Comparing the transfer integrals in protein and in gas phase, we see that the unidirectionality can be explained without the protein effect. The protein effect is far from the origin of the asymmetry of the electronic factor. To analyze the asymmetry origin, we approximate the transfer integral for the ET from $\mathrm{P}^{*}$ to $\mathrm{B}$ in a gas phase by the Fock matrix element, $f_{\mathrm{LPLB}}$, where LP and LB denotes the LUMOs of $\mathrm{P}$ and $\mathrm{B}$, respectively, and further this element is decomposed into the sum of the atomic contributions of the atoms belonging to $\mathrm{B}$ as

$$
\begin{gathered}
f_{\mathrm{LPLB}}=\sum_{\mathrm{X} \in \mathrm{Bs} \in \mathrm{X} \in \mathrm{r} \in \mathrm{P}} C_{\mathrm{rLP}} C_{\mathrm{sLB}} f_{\mathrm{rs}} \\
=\sum_{\mathrm{X} \in \mathrm{B}} f_{\mathrm{LPLB}}^{\mathrm{X}}
\end{gathered}
$$

where $f_{\mathrm{LPLB}}^{\mathrm{X}}$ is the contribution of the atom $\mathrm{X}$ of $\mathrm{B}, C$ is the MO coefficient and $f_{\mathrm{rs}}(\mathrm{r} \in \mathrm{P}$ and $s \in \mathrm{B})$ is an AO Fock matrix element. Note that, in the preceding sections, the transfer integral is used in a squared form, but in the following analysis it is used in a form of eq 8-1.

It is clear from eq 8-1 that the following three conditions must be satisfied for the transfer integral $f_{\text {LPLB }}$ to be large. The first one is the proximity condition. In order that $f_{\mathrm{rs}}$ has a large value, the atomic orbitals $r$ and $s$ should be closely located, since $f_{\mathrm{rs}}$ depends exponentially on the distance between $\mathrm{r}$ and $\mathrm{s}$. The second one is the MO coefficient condition: namely the product of the $\mathrm{MO}$ coefficients between the chromophores $C_{\mathrm{rLP}}{ }^{-}$ $C_{\text {sLB }}$ should be large. The third one is the nodal effect which originates from the nodal character of the MOs. The summation over the AOs may lead to a cancellation if the MO coefficients have opposite signs due to some symmetry. This nodal effect may be large when the donor or acceptor orbitals have nodal structure as in porphyrin compounds.

The result of the decomposition of $f_{\mathrm{LPLB}}$ is shown in Figure 3a. We see that $\mathrm{B}_{\mathrm{L}}$ has much larger atomic contributions than $\mathrm{B}_{\mathrm{M}}$ and that the largest difference arises from the contributions of rings III and II of B's and that the largest atomic contribution is due to the 6-carbon of ring III of $\mathrm{B}_{\mathrm{L}}\left(10.8 \times 10^{-5}\right)$, while the largest contribution in $\mathrm{B}_{\mathrm{M}}$ is due to $\beta$-carbon $\left(-6.4 \times 10^{-5}\right)$.

Now, what is the origin of the asymmetry in the transfer integrals between $\mathrm{P}$ and $\mathrm{B}_{\mathrm{L}}$ and between $\mathrm{P}$ and $\mathrm{B}_{\mathrm{M}}$ ? Figure 4 shows the geometries and the LUMO populations of $\mathrm{P}, \mathrm{B}_{\mathrm{L}}$, and $\mathrm{B}_{\mathrm{M}}$. First we examine the geometrical proximity factor. Rings III of $B_{L}$ and $B_{M}$ are located close to rings $I$ of $P_{M}$ and $P_{L}$, respectively. The center-to-center distances are 6.89 and 7.41 $\AA$, respectively, and therefore, the $\mathrm{L}$ side is closer than the $\mathrm{M}$ side by $0.5 \AA$. Rings II of $\mathrm{B}_{\mathrm{L}}$ and $\mathrm{B}_{\mathrm{M}}$ are close to rings $\mathrm{V}$ of $\mathrm{P}_{\mathrm{L}}$ and $\mathrm{P}_{\mathrm{M}}$, respectively, and in particular, the $4 \mathrm{a}$-carbon of $\mathrm{B}_{\mathrm{L}}$ is located at $4.7 \AA$ from the $\gamma$-carbon of $P_{L}$. However, in this case, the $\mathrm{P}_{\mathrm{L}}-\mathrm{B}_{\mathrm{L}}$ and $\mathrm{P}_{\mathrm{M}}-\mathrm{B}_{\mathrm{M}}$ center-to-center distances are similar: 7.13 and $7.14 \AA$, respectively.

We next examine the MO coefficient condition using the MO populations of the LUMO's of $\mathrm{P}$ and B shown in Figure 4, where the sign of the population indicates the phase of the orbital. For the B's, the populations are almost the same between the $\mathrm{L}$ and $\mathrm{M}$ sides: some amplitudes are calculated at 5- and 6-carbons of ring III, but 4- and 4a-carbons of ring II have almost no populations. For $\mathrm{P}$, the population gathers in the vicinity of ring $I$ of $P_{L}$ than in that of $P_{M}$, which favors the M-side ET.

From the above analyses of both the geometrical proximity condition and the MO coefficient condition, we conclude that the asymmetry in the contributions of rings III of $B_{L}$ and $B_{M}$ depicted in Figure 3 is attributed to be due to the geometrical proximity effect. The distance between rings III of $\mathrm{B}_{\mathrm{L}}$ and ring I of $\mathrm{P}_{\mathrm{M}}$ is closer by $0.5 \AA$ than the distance between ring III of $\mathrm{B}_{\mathrm{M}}$ and ring $\mathrm{I}$ of $\mathrm{P}_{\mathrm{L}}$. The proximity condition overwhelms the MO coefficient condition, since the latter favors the M-side ET. On the other hand, the asymmetry in the contributions of rings II of $B_{L}$ and $B_{M}$ shown in Figure 3 is due to the MO coefficient condition. As seen in Figure 4, the LUMO of $\mathrm{P}$ is slightly localized on the $\gamma$-carbon of $\mathrm{P}_{\mathrm{L}}$, which lies closely to the 4- 


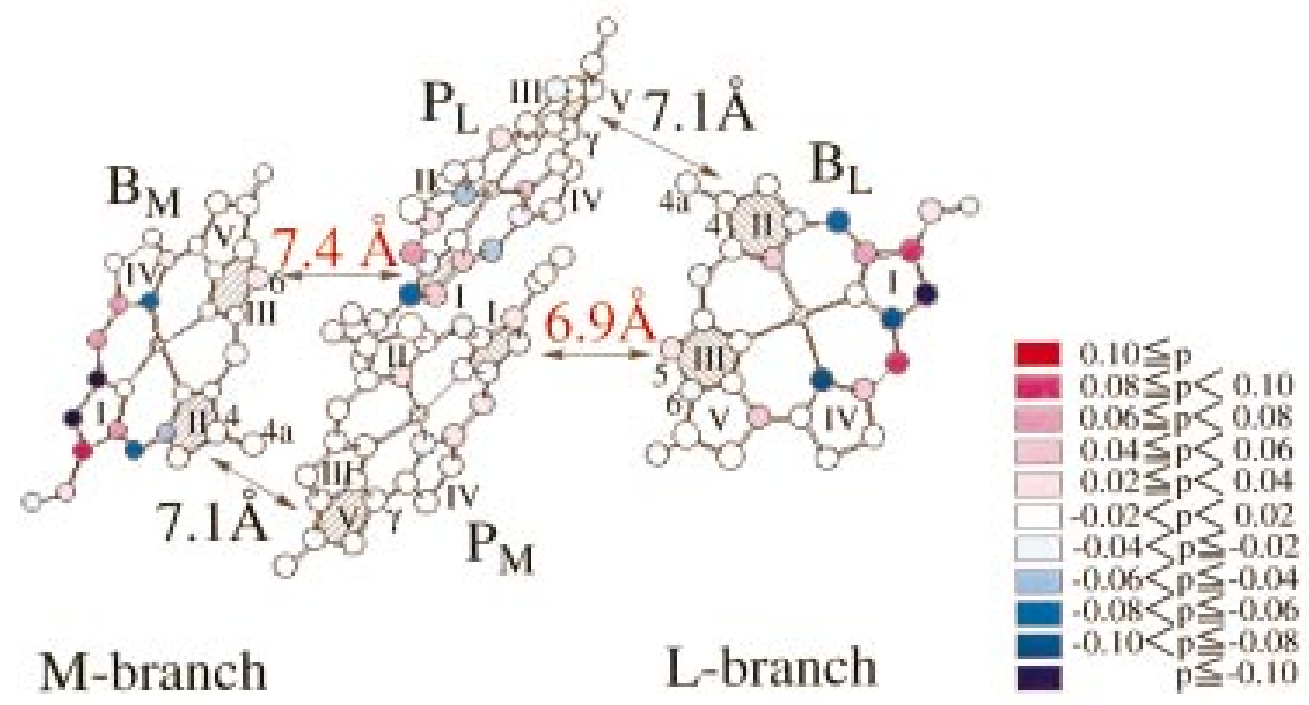

Figure 4. Geometries and LUMO populations of $\mathrm{P}, \mathrm{B}_{\mathrm{L}}$, and $\mathrm{B}_{\mathrm{M}}$. The sign of the population indicates the phase of the orbital.

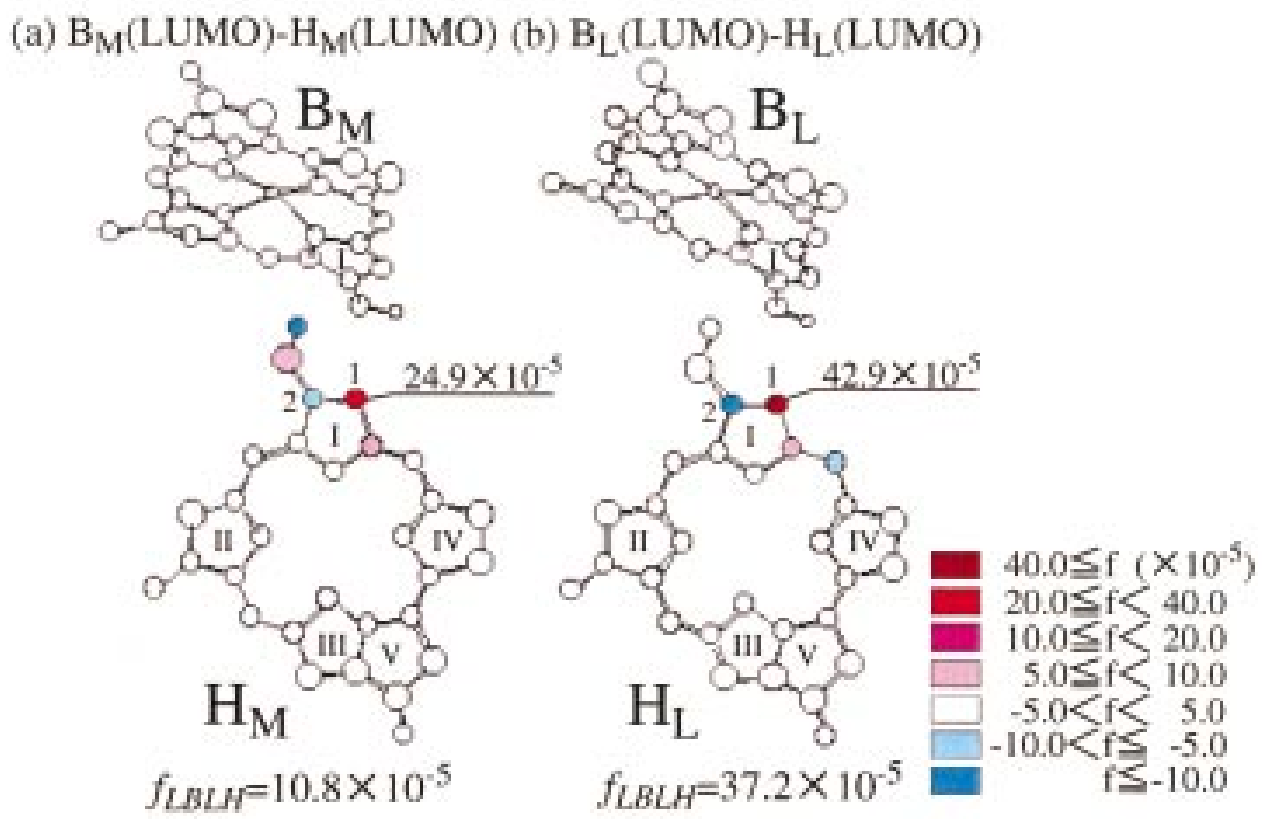

Figure 5. Atomic contributions of $H$ for the transfer integrals between $B$ and $H$.

and $4 \mathrm{a}$-carbons of $\mathrm{B}_{\mathrm{L}}$. In this case, the distance between ring II of $\mathrm{B}_{\mathrm{L}}$ and ring $\mathrm{V}$ of $\mathrm{P}_{\mathrm{L}}$ is similar to the corresponding distance between $\mathrm{B}_{\mathrm{M}}$ and $\mathrm{P}_{\mathrm{M}}$ as described above. Accordingly, the contributions of the $4 \mathrm{a}$ - and 4-carbons of ring II of $\mathrm{B}_{\mathrm{L}}$ is due to the MO coefficient asymmetry.

Between the above two factors, the ring III and ring II contributions of $\mathrm{B}_{\mathrm{L}}$ and $\mathrm{B}_{\mathrm{M}}$, the ring III contribution is larger than the ring II contribution as seen from Figure 3, and therefore, the origin of the asymmetry in the transfer integrals between $\mathrm{P}$ and $\mathrm{Bs}$ is attributed to the proximity condition, i.e., to the 0.5 $\AA$ difference in the rings I-III distances shown in Figure 4.

B. Factor for the ET from B to $\mathbf{H}$. The calculated transfer integrals for the ET from $\mathrm{B}$ to $\mathrm{H}$ is also larger in the $\mathrm{L}$ side than in the $\mathrm{M}$ side. Figure 5 shows the analysis of the Fock matrix element $f_{\mathrm{LBLH}}$ between the LUMO of B and the LUMO of $\mathrm{H}$ into the atomic contributions. The largest contributions are $42.9 \times 10^{-5}$ and $24.9 \times 10^{-5}$ au of the 1 -carbons of rings I of $\mathrm{H}_{\mathrm{L}}$ and $\mathrm{H}_{\mathrm{M}}$, respectively.

In Figure 6, the MO populations of the LUMO's of B and H in the L- and M-branches are shown. The MO populations are quite symmetric between the L- and M-regions. In both L- and $\mathrm{M}$-regions, the most populated rings $\mathrm{I}$ of $\mathrm{B}$ and $\mathrm{H}$ are adjacent to each other, so that the transfer integrals can be large upon the fulfillment of the MO coefficient condition. Actually, the transfer integral from $\mathrm{B}_{\mathrm{L}}$ to $\mathrm{H}_{\mathrm{L}}$ is twice (in square four times) as large as that from $\mathrm{P}$ to $\mathrm{B}_{\mathrm{L}}$. In a previous semiempirical study, ${ }^{7}$ the transfer integral was calculated to be equal between $\mathrm{P}$ to $\mathrm{B}$ and $\mathrm{B}$ to $\mathrm{H}$, which is different from the present result and from the experimentally estimated values.

The center-to-center distances between the porphyrin rings of $\mathrm{B}$ and $\mathrm{H}$ are 10.7 and $10.6 \AA$ for the L- and M-branches, respectively, which are almost the same. However, the orientation of $\mathrm{H}_{\mathrm{L}}$ and $\mathrm{H}_{\mathrm{M}}$ are somehow different. The distance between the 1-carbons of $\mathrm{B}$ and $\mathrm{H}$, both having the largest coefficient in their LUMO's, are 5.03 and $5.46 \AA$ in the $\mathrm{L}$ and $\mathrm{M}$ sides, respectively: the $\mathrm{L}$ side is closer by $0.43 \AA$ than the $\mathrm{M}$ side. This proximity in the $\mathrm{L}$ side owing to the orientational difference results in a large asymmetry in the transfer integral through the asymmetry of the atomic contribution of the 1-carbon, in particular. 


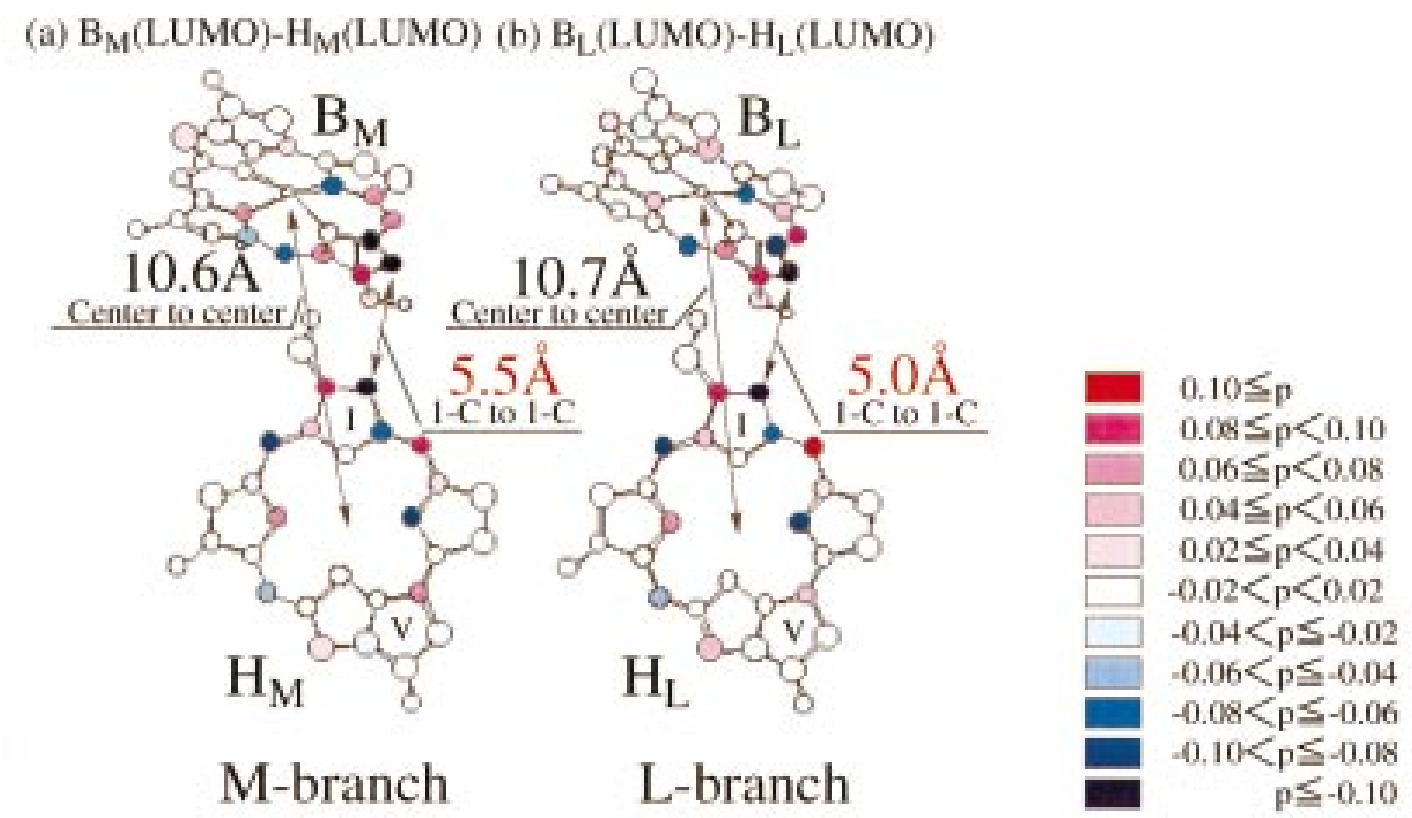

Figure 6. Geometries and LUMO populations for (a) $\mathrm{B}_{M}$ and $\mathrm{H}_{\mathrm{M}}$ and (b) $\mathrm{B}_{\mathrm{L}}$ and $\mathrm{H}_{\mathrm{L}}$. The sign of the population indicates the phase of the orbital.
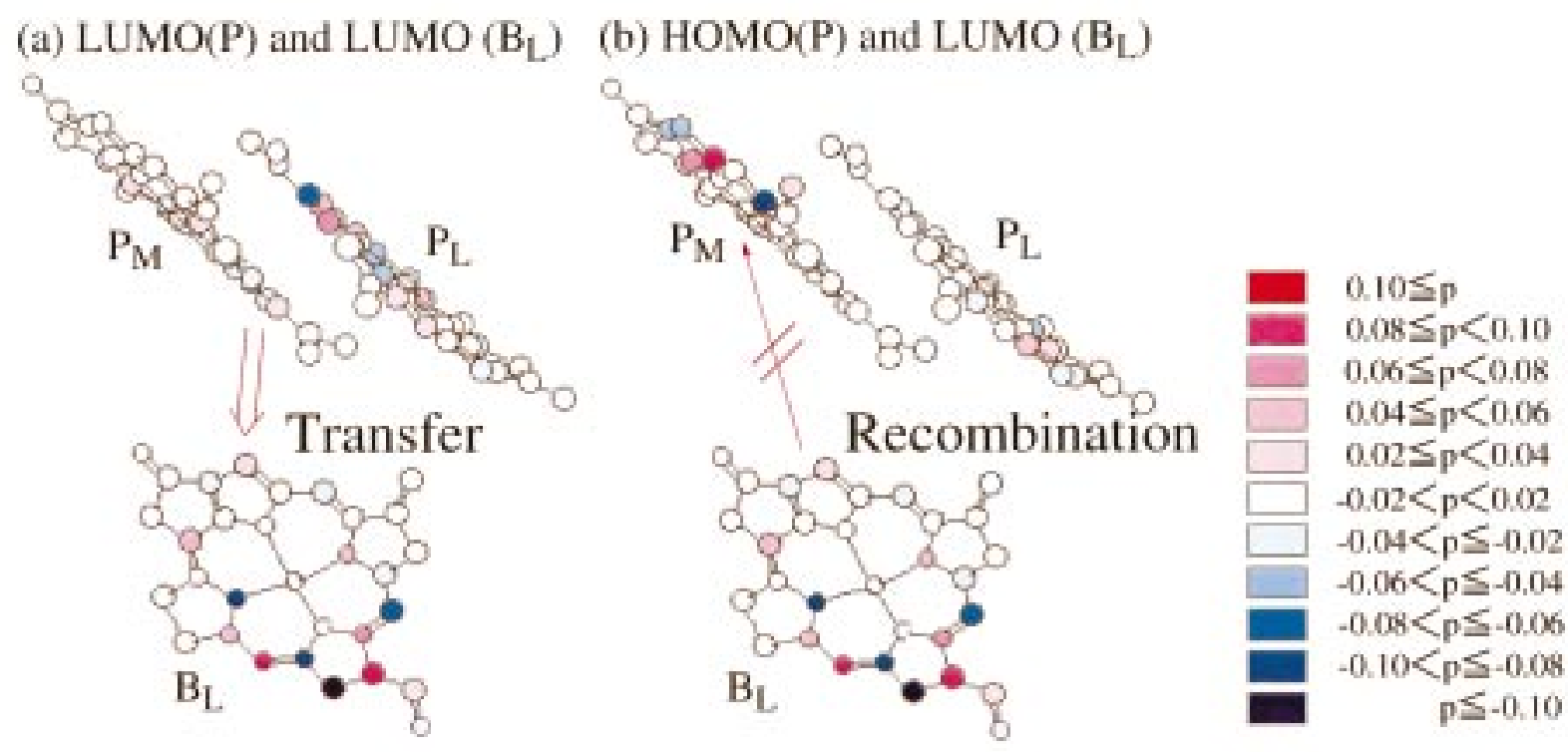

Figure 7. $\mathrm{MO}$ populations of (a) LUMOs of $\mathrm{P}$ and $\mathrm{B}_{\mathrm{L}}$ and (b) HOMO of $\mathrm{P}$ and LUMO of $\mathrm{B}_{\mathrm{L}}$. The sign of the population indicates the phase of the orbital.

We note a role of the nodal condition for this case, though it is of secondary importance as seen from Figure 5. The atomic contributions between 1- and 2-carbons of ring I of H's have opposite signs and are canceling, though incomplete. Namely, the LUMOs of H's have nodes between the 1- and 2-carbons, which make their contributions different in sign.

This orientational asymmetry between $\mathrm{H}_{\mathrm{L}}$ and $\mathrm{H}_{\mathrm{M}}$ may be attributed to the difference in the specific protein environments surrounding H's. $\mathrm{H}_{\mathrm{L}}$ has a glutamate side chain (GLU L104) near the carbonyl group at ring V. The GLU L104 is thought to have a hydrogen bond with the oxygen of the carbonyl group ${ }^{42,43}$ and may control the orientation of $\mathrm{H}_{\mathrm{L}}$, while in the M-branch, GLU L104 is replaced with valine (M131) ${ }^{2,8}$ which has no polar group.

C. Factor for the $\mathbf{C R}$ from $\mathbf{B}$ to $\mathbf{P}$. The transfer integral for the $\mathrm{CR}$ from $\mathrm{B}_{\mathrm{L}}$ to $\mathrm{P}$ is much smaller than that of the ET as shown in Figure 2, though both transfers are between the same chromophores: the interatomic distances are the same between the two processes. The ET occurs from the LUMO of $\mathrm{P}$ to the LUMO of B, while the CR occurs from the LUMO of B to the $\mathrm{HOMO}$ of $\mathrm{P}$, and therefore the key difference should arise from the HOMO and LUMO of P. In Figure 3b, the Fock matrix element for the CR process, $f_{\mathrm{HPLB}}(\mathrm{HP}=\mathrm{HOMO}$ of $\mathrm{P}$ and $\mathrm{LB}$ $=\mathrm{LUMO}$ of $\mathrm{B})$, is analyzed and compared with the analysis for the ET reaction shown in Figure 3a. The ring III contribution is reduced and a cancellation of the atomic contributions occurs, resulting in a reduction of the total transfer integral.

In Figure 7, the population of the HOMO of $\mathrm{P}$ is compared with that of the LUMO of P. In the HOMO, the electron is localized in the upper part of $\mathrm{P}_{\mathrm{M}}$ and the sign is different between $\mathrm{P}_{\mathrm{M}}$ and $\mathrm{P}_{\mathrm{L}}$, while in the LUMO the electron is localized in the lower part of both $\mathrm{P}_{\mathrm{M}}$ and $\mathrm{P}_{\mathrm{L}}$. Therefore, the distance between the electron clouds of $\mathrm{P}$ and $\mathrm{B}$ is larger in the HOMO(P)-LUMO(B) pair than in the $\operatorname{LUMO}(\mathrm{P})-\mathrm{LUMO}(\mathrm{B})$ pair. 
Further, the antisymmetry between $\mathrm{P}_{\mathrm{M}}$ and $\mathrm{P}_{\mathrm{L}}$ of the HOMO of $P$ causes a cancellation of the atomic contribution in the transfer integral. Thus, due to the MO coefficient condition and the nodal effect, the transfer integral for the CR is much smaller than that of the ET. Thus, the inefficiency of the CR process, which implies the efficiency of the ET process, is regulated by the difference in the localization between the HOMO and the LUMO of P.

\section{Summary and Concluding Remarks}

We have studied in this paper the mechanism of the ET and the origin of its unidirectionality in the PSRC of Rps. viridis from $\mathrm{ab}$ initio point of view. We have examined the ET process from $\mathrm{P}^{*}$ to $\mathrm{H}$ through $\mathrm{B}$ in the sequential mechanism. The $\mathrm{CR}$ process from $\mathrm{B}^{-}$to $\mathrm{P}^{+}$is also examined. The electronic factors were calculated by the SAC/SAC-CI method which is able to calculate various electronic states of the chromophores of the PSRC in a reasonable accuracy. The effect of the surrounding proteins and waters was calculated by using the point-charge model.

The unidirectionality of the electron transfer is explained by the asymmetry of the transfer integrals, an electronic factor, for the ETs from $\mathrm{P}$ to $\mathrm{B}$ and from $\mathrm{B}$ to $\mathrm{H}$ as shown in Figure 2. The ratios of the transfer integrals between the L- and M-regions are 15.2 and 6.56 for $\mathrm{P}$ to $\mathrm{B}$ and $\mathrm{B}$ to $\mathrm{H}$, respectively (Table 5). The ET from $\mathrm{B}_{\mathrm{L}}$ to $\mathrm{H}_{\mathrm{L}}$ is very efficient since the corresponding transfer integral is very large, 104. The efficient feature of the ET is also explained by the smallness of the CR process from $\mathrm{P}^{+} \mathrm{B}^{-}$to $\mathrm{PB}$.

We failed, however, to explain the energy levels of the electron transferred states due to an inability of calculating the relaxation energies of the chromophores and the protein medium, the last two terms of eq 4-1, by our present ab initio methodology. Reliable ab initio calculations of such quantities are certainly very interesting subject to be solved in future. Thus, in the present study, we analyze the mechanisms of the electron transfer and its unidirectionality only through the electronic factor of eq 1-1, which is valid, for example, when the matching condition is always satisfied.

The transfer integrals are analyzed by decomposing them into the atomic contributions and the three conditions, the proximity condition, the MO coefficient condition, and the nodal effect are pointed out to be important. For the ET from $\mathrm{P}$ to $\mathrm{B}$, the most important factor is the geometrical asymmetry between $\mathrm{P}$ and B's in the L- and M-branches (the proximity condition). The L-side distance between ring $\mathrm{I}$ of $\mathrm{P}_{\mathrm{M}}$ and ring III of $\mathrm{B}_{\mathrm{L}}$, which fulfill the MO coefficient condition, is closer by $0.5 \AA$ than that in the M-side (see Figure 4). Since the transfer integral depends exponentially on the distance, this local geometric asymmetry causes a large difference. The MO coefficient asymmetry is another factor. For the ET from B to $\mathrm{H}$, the asymmetry is attributed again to the geometric factor (the proximity condition): though the average distance between $\mathrm{B}$ and $\mathrm{H}$ is almost the same between the $\mathrm{M}$ - and L-branches, the orientation of $\mathrm{H}$ relative to $\mathrm{B}$ is asymmetric and therefore the distance between ring $\mathrm{I}$ of $\mathrm{B}$ and ring $\mathrm{I}$ of $\mathrm{H}$ is closer by $0.5 \AA$ in the L-branch than in the M-branch. The most efficient ET route is from 1-carbon of ring $\mathrm{I}$ of $\mathrm{B}_{\mathrm{L}}$ to 1-carbon of ring $\mathrm{I}$ of $\mathrm{H}_{\mathrm{L}}$ (see Figures 5 and 6 ). The smallness of the $\mathrm{CR}$ process from $\mathrm{P}^{+} \mathrm{B}^{-}$to $\mathrm{PB}$ is attributed to the difference in the orbital localization between the LUMO and the HOMO of P (see Figure 7).
Thus, basically, the unidirectionality of the ET is understood to be due to the asymmetry in the three-dimensional arrangement of the chromophores in the PSRC. The L-side chromophores are locally closer than the M-side ones, though the average separations are almost the same between the L- and M-regions. The asymmetry in the MO distribution between the L- and Mregions is also a factor, but less important, since the exponential dependence of the transfer integral on the distance is much steeper than the variations in the MO coefficients between the $\mathrm{L}$ - and M-sides. On the other hand, the inefficiency of the CR is definitely due to the difference in the electron localization between the HOMO and the LUMO of P: the origin is very much quantum.

As far as the present analysis is correct, the protein environment plays a decisive role, since the three-dimensional arrangements of the chromophores in the L- and M-branches are supported by the proteins. However, the protein effects accounted for by the electrostatic point-charge model were found to be very small for the electron distributions in the chromophores and for the transfer integrals between the chromophores.

Thus, now that the origin of the L-branch selectivity of the ET in the PSRC of Rps. viridis is attributed to the local closeness of the chromophores in the L-region relative to the M-region, we propose to do a mutation experiment to make the M-side chromophores locally closer to each other than the L-side ones, which should realize the M-side selectivity of the ET. Nature offered a duality in the electron path, but only one is utilized now. To realize the another path is certainly an exciting experiment, which will lead to clarify many other facts.

Acknowledgment. This study was supported in part by a Grant-in-Aid for Scientific Research from the Japanese Ministry of Education, Science, Culture, and Sports, and by the New Energy and Industrial Technology Development Organization (NEDO). J. H. gratefully acknowledges the research fellowships from the Japan Society for the Promotion of Science (JSPS).

\section{Appendix}

The CT state, $\mathrm{P}^{+} \mathrm{B}^{-}$, defined by eq $2-6$, is not a pure singlet state, since it is defined by a product of the two doublet wave functions, $\mathrm{P}^{+}$and $\mathrm{B}^{-}$. In eq $2-6$, the operators $I^{\mathrm{P}}$ and $E^{\mathrm{B}}$ are the sums of the single (S) and double (D) ionization and electron attachment operators

$$
\begin{aligned}
I^{\mathrm{P}} & =\sum_{I}^{\mathrm{P}} C_{I}^{\mathrm{P}}(\mathrm{S}) I_{I}^{\mathrm{P}}(\mathrm{S})+\sum_{I}^{\mathrm{P}} \sum_{J}^{\mathrm{P}} C_{I J}^{\mathrm{P}}(\mathrm{D}) I_{I}^{\mathrm{P}}(\mathrm{S}) R_{J}^{\mathrm{P}}(\mathrm{S}) \\
& =\sum_{I}^{\mathrm{P}} I_{I}^{\mathrm{P}}(\mathrm{S})\left\{C_{I}^{\mathrm{P}}(\mathrm{S})+\sum_{j}^{\mathrm{P}} C_{I J}^{\mathrm{P}}(\mathrm{D}) R_{J}^{\mathrm{P}}(\mathrm{S})\right\} \\
E^{\mathrm{B}} & =\sum_{I}^{\mathrm{B}} C_{I}^{\mathrm{B}}(\mathrm{S}) E_{I}^{\mathrm{B}}(\mathrm{S})+\sum_{I}^{\mathrm{B}} \sum_{J}^{\mathrm{B}} C_{I J}^{\mathrm{B}}(\mathrm{D}) E_{I}^{\mathrm{B}}(\mathrm{S}) R_{J}^{\mathrm{B}}(\mathrm{S}) \\
& =\sum_{I}^{\mathrm{B}} E_{I}^{\mathrm{B}}(\mathrm{S})\left\{C_{I}^{\mathrm{B}}(\mathrm{S})+\sum_{j}^{\mathrm{B}} C_{I J}^{\mathrm{B}}(\mathrm{D}) R_{J}^{\mathrm{B}}(\mathrm{S})\right\}
\end{aligned}
$$

where $I_{I}^{\mathrm{P}}, E_{I}^{\mathrm{B}}$, and $R_{I}^{\mathrm{P}}$ are ionization, electron attachment, and singlet excitation operators, respectively. Using eq A-1 and A-2, 
eq 2-6 is rewritten as

$$
\begin{aligned}
\Psi^{\mathrm{P}^{+} \mathrm{B}^{-}} & =\sum_{I}^{\mathrm{P}} \sum_{K}^{\mathrm{B}} I_{I}^{\mathrm{P}}(\mathrm{S}) E_{K}^{\mathrm{B}}(\mathrm{S})\left\{C_{I}^{\mathrm{P}}(\mathrm{S})+\sum_{J}^{\mathrm{P}} C_{I J}^{\mathrm{P}}(\mathrm{D}) R_{J}^{\mathrm{P}}(\mathrm{S})\right\} \times \\
& \left\{C_{K}^{\mathrm{B}}(\mathrm{S})+\sum_{L}^{\mathrm{B}} C_{K L}^{\mathrm{B}}(\mathrm{D}) R_{L}^{\mathrm{B}}(\mathrm{S})\right\} \exp \left(S^{\mathrm{P}}+S^{\mathrm{B}}\right) \Phi_{0}^{\mathrm{P}+\mathrm{B}}(\mathrm{A}-3)
\end{aligned}
$$

Here, the products of the excitator, $I_{\mathrm{I}}^{\mathrm{P}}(\mathrm{S}) E_{\mathrm{K}}^{\mathrm{B}}(\mathrm{S})$, are written as

$$
I_{I}^{\mathrm{P}}(\mathrm{S}) E_{K}^{\mathrm{B}}(\mathrm{S})=a_{i a} a_{a a}^{\dagger}
$$

which is not a singlet operator, so that a spin contamination occurs in eq A-3. We therefore introduce the spin-symmetry adapted operator $R_{\mathrm{I}}^{\mathrm{P}+\mathrm{B}}$ as

$$
R_{I}^{\mathrm{P}+\mathrm{B}}(\mathrm{S}) \equiv \frac{1}{\sqrt{2}}\left(a_{i a} a_{a a}^{\dagger}+a_{i \beta} a_{a \beta}^{\dagger}\right)
$$

in which the $\beta$-counterpart is added to eq A-4. Then, the pure singlet state of $\mathrm{P}^{+} \mathrm{B}^{-}$is written as

$$
\begin{aligned}
\Psi^{\mathrm{P}^{+} \mathrm{B}^{-}}= & \sum_{I}^{\mathrm{P}+\mathrm{B}} R_{I}^{\mathrm{P}+\mathrm{B}}(\mathrm{S})\left\{C_{I}^{\mathrm{P}}(\mathrm{S})+\sum_{J}^{\mathrm{P}} C_{I J}^{\mathrm{P}}(\mathrm{D}) R_{J}^{\mathrm{P}}(\mathrm{S})\right\} \times \\
& \left\{C_{I}^{\mathrm{B}}(\mathrm{S})+\sum_{J}^{\mathrm{B}} C_{I J}^{\mathrm{B}}(\mathrm{D}) R_{J}^{\mathrm{B}}(\mathrm{S})\right\} \exp \left(S^{\mathrm{P}}+S^{\mathrm{B}}\right) \Phi_{0}^{\mathrm{P}+\mathrm{B}}
\end{aligned}
$$

\section{References and Notes}

(1) Voet, D.; Voet, J. G. Biochemistry, 2nd ed.; John Wiley \& Sons: New York, 1995; Chapter 22.

(2) Deisenhofer, J.; Epp, O.; Miki, K.; Huber, R.; Michel, H. J. Mol. Biol. 1984, 180, 385 .

(3) Hörber, J. K. H.; Göbel, W.; Ogrodnik, A.; Michel-Beyerle, M. E.; Knapp, F. W. In Antennas and Reaction Centers of Photosynthetic Bacteria; Michel-Beyerle, M. E., Ed.; Springer-Verlag: Berlin, 1985; pp 292.

(4) Hörber, J. K. H.; W. Göbel; Ogrodnik, A.; Michel-Beyerle, M. E.; Cogdell, R. J. FEBS Lett. 1986, 198, 268.

(5) Marcus, R. A.; Sutin, N. Biochim. Biophys. Acta 1985, 811, 265 8210 .

(6) Thompson, M. A.; Zerner, M. C. J. Am. Chem. Soc. 1992, 113

(7) Scherer, O. J.; Scharnagl, C.; Fischer, S. F. Chem. Phys. 1995, 197,

(8) Michel-Beyerle, M. E.; Plato, M.; Deisenhofer, J.; Michel, H.; Bixon, M.; Jortner, J. Biochim. Biophys. Acta 1988, 932, 52. 4277.

(9) Gunner, M. R.; Nicholls, A.; Honig, B. J. Phys. Chem. 1996, 100,

(10) Marchi, M.; Gehlen, J. N.; Chandler, D.; Newton, M. D. J. Am. Chem. Soc. 1993, 115, 4178.

(11) Plato, M.; Möbius, K.; Michel-Beyerle, M. E.; Bixon, M.; Jortner, J. J. Am. Chem. Soc. 1988, 110, 7279.

(12) Nakatsuji, H.; Hirao, K. J. Chem. Phys. 1978, 68, 2053.

(13) Nakatsuji, H. Chem. Phys. Lett. 1978, 59, 362; 1979, 67, 329; 1979 67,334 .

(14) Nakatsuji, H.; Hirao, K.; Mizukami, M. Chem. Phys. Lett. 1991, $179,555$.

(15) Nakatsuji, H. Acta Chim. Hung. 1992, 129, 719.

(16) Nakatsuji, H. In Computational Chemistry, Reviews of Current Trends; Leszczynski, J., Ed.; World Scientific: Singapore, 1996; Vol. 2, pp $62-124$.
(17) Nakatsuji, H.; Hasegawa, J.; Hada, M. J. Chem. Phys. 1996, 104, 2321; Tokita, Y.; Hasegawa, J.; Nakatsuji, H. J. Phys. Chem. A 1998, 102 1843 .

(18) Hasegawa, J.; Hada, M.; Nonoguchi, M.; Nakatsuji, H. Chem. Phys. Lett. 1996, 250, 159.

(19) Hasegawa, J.; Ozeki, Y.; Ohkawa, K.; Hada, M.; Nakatsuji, H. J. Phys. Chem. B 1998, 102, 1320.

(20) Nakatsuji, H.; Tokita, Y.; Hasegawa, J.; Hada, M. Chem. Phys. Lett. 1996, 256, 220 .

(21) Tokita, Y.; Nakatsuji, H. J. Phys. Chem. B. 1997, 101, 3281.

(22) Toyota, K.; Hasegawa, J.; Nakatsuji, H. J. Phys. Chem. A 1997 $101,446$.

(23) Hasegawa, J.; Ohkawa, K.; Nakatsuji, H. J. Phys. Chem. B 1998 , 102,10410 .

(24) Nakatsuji, H.; Hasegawa, J.; Ohkawa, K. Chem. Phys. Lett. 1998 In press.

(25) Breton, J. Biochim. Biophys. Acta 1985, 810, 235.

(26) Abola, E. E.; Bernstein, F. C.; Bryant, S. H.; Koetzle, T. F.; Weng, J. Protein Data Bank, In Crystallographic Databases-Information Content, Software Systems, Scientific Applications; Allen, F. H., Bergerhoff, G., Sievers, R., Eds.; Data Commission of the International Union of Crystallography: Chester, 1987; pp 107-132. Bernstein, F. C.; Koetzle, T. F.; Williams, G. J. B.; Meyer, E. F., Jr.; Brice, M. D.; Rodgers, J. R.; Kennard, O.; Shimanouchi, T.; Tasumi, M. The Protein Data Bank: A ComputerBased Archival File for Macromolecular Structures. J. Mol. Biol. 1977, 112,535 .

(27) Huzinaga, S.; Andzelm, J.; Klobukowski, M.; Radzio-Andzelm, E.; Sakai, Y.; Tatewaki, H. Gaussian Basis Set for Molecular Calculations; Elsevier: NewYork, 1984.

(28) Huzinaga, S.; J. Chem. Phys. 1965, 42, 1293.

(29) Cornell, W. D.; Cieplak, P.; Bayly, C. I.; Gould, I. R.; Merz, K. M.; Freguson, D. R.; Spellmeyer, D. C.; Fox, T.; Caldwell, J. W.; Kollman, P. A. J. Am. Chem. Soc. 1995, 117, 5179.

(30) Jorgensen, W. L.; Chandrasekhar, J.; Madura, J. D.; Impey, R. W.; M. L. Klein, J. Chem. Phys. 1983, 79, 926.

(31) Nakatsuji, H. Chem. Phys. 1983, 75, 425

(32) Dupuis, M.; Farazdel, A. MOTECC-91; Center for Scientific and Engineering Computations: IBM Corporation, 1991.

(33) Nakatsuji, H.; Hada, M.; Ehara, M.; Hasegawa, J.; Nakajima, T.; Nakai, H.; Kitao, O.; Toyota, K. SAC/SAC-CI Program System (SACC196) for Calculating Ground, Excited, Ionized, and Electron Attached States and Singlet to Septet Spin Multiplicities; 1998. To be submitted for publication.

(34) Nakatsuji, H. Program system for SAC and SAC-CI calculations. Program Library No. 146(Y4/SAC); Data Proccessing Center of Kyoto University: Kyoto, Japan, 1985; Program Library SAC85; No. 1396; Computer Center of the Institute for Molecular Science: Okazaki, 1981.

(35) Tanaka S.; Marcus, R. A. J. Phys. Chem. B. 1997, 101, 5031.

(36) Nakajima, T.; Nakatsuji, H. Chem. Phys. Lett. 1998. In press.

(37) Schmidt, S.; Arlt, T.; Hamm, P.; Huber, H.; Nägele, T.; Wachtveitl, J.; Meyer, M.; Scheer, H.; Zinth, W. Chem. Phys. Letters 1994, 223, 116

(38) Schmidt, S.; Arlt, T.; Hamm, P.; Huber, H.; Nägele, T.; Wachtveitl, J.; Meyer, M.; Scheer, H.; Zinth, W. Spectrochim. Acta 1995, 51A, 1565.

(39) Gunner, M. R.; Dutton, P. L. J. Am. Chem. Soc. 1989, 111, 3400.

(40) The transfer integral of the $\mathrm{CR}$ reaction from $\mathrm{P}^{+}\left(1^{1} \mathrm{~A}\right) \mathrm{H}^{-}\left(1^{1} \mathrm{~A}\right)$ state (called state 3 ) to the ground state (called state 0 ) would be evaluated by the superexchange mechanism, since $\mathrm{P}^{+}\left(1^{1} \mathrm{~A}\right) \mathrm{B}^{-}\left(1^{1} \mathrm{~A}\right)$ state (called state 2$)$ should be energetically higher than the $\mathrm{P}^{+}\left(1^{1} \mathrm{~A}\right) \mathrm{H}^{-}\left(1^{1} \mathrm{~A}\right)$ state. In this case, the transfer integral is expressed as $H_{30}=H_{32} H_{20} / \Delta E_{32}$ where $H_{\mathrm{mn}}$ denotes the transfer integral between states $\mathrm{m}$ and $\mathrm{n}$ and $\Delta E_{32}$ is the energy difference between the states 3 and 2 . In this case, only state 2 is considered as a virtual intermediate state and for $\Delta E_{32}$ the value previously reported ${ }^{37}$ is used.

(41) Bixon, M.; Jortner, J.; Michel-Beyerle, M. E. The Photosynthetic Bacterial Reaction Center; Breton, J., Vermeglio, A., Eds.; Plenum Press: New York, 1992.

(42) Lutz, M.; Robert, B. In Antennas and Reaction Centers of Photosynthetic Bacteria; Michel-Beyerle, M. E., Ed.; Springer-Verlag. Berlin, 1985; p 138.

(43) Feher, G.; Isaacson, R. A.; Okamura, M. Y.; Lubitz, W. Biophys. J. 1987, 51, 337a. 